\title{
Statistical predictability of Niño indices for two types of ENSO
}

\author{
Hong-Li Ren ${ }^{1,2} \cdot$ Jinqing Zuo ${ }^{1,3} \cdot$ Yi Deng $^{4}$
}

Received: 4 June 2018 / Accepted: 17 September 2018 / Published online: 29 September 2018

(c) The Author(s) 2018

\begin{abstract}
The El Niño-Southern Oscillation (ENSO) has been shown to manifest as primarily two types, the eastern Pacific (EP) type and central Pacific (CP) type, in terms of the zonal positions of the sea surface temperature (SST) anomalies. This study focuses on examining the predictability of the two types of ENSO by developing statistical models for their corresponding Niño indices, which have their own distinct key precursors. The results show that the statistical predictability of the Niño indices representing the two types of ENSO primarily originates from the preceding variations in the equatorial Pacific upper-ocean heat content and the surface zonal wind stress, which intrinsically reflect the zonally uniform and contrasted thermocline patterns, respectively. The traditional Niño3 and Niño4 indices are more predictive than the Niño indices of the EP and CP ENSO types; however, all the indices are subject to predictability barriers with different timings and intensities, which might be weakened by introducing additional external precursors. The EP ENSO indices have overall higher skills than the CP indices, in which the statistical model has much higher skill scores than persistence forecast for the EP ones while it does less for the CP ones. We demonstrate that the precursors outside the tropical Pacific, e.g., the Indian Ocean Dipole, North Pacific oscillation, North American dipole, and Southern Hemispheric SST modes, except the northern tropical Atlantic SST, as suggested in previous studies, only make limited contributions to improving the prediction skills of the two ENSO types at specific initial months and leads compared to a benchmark model built using the equatorial Pacific heat content and zonal wind stress indices. This is primarily because these precursors have already transferred most of their signals into the variation of the two indices in the benchmark model. We further show that conditionally adding the northern tropical Atlantic SST precursor to the benchmark could provide considerable additional prediction skill scores for both types of ENSO and weaken the intensity of the ENSO predictability barriers that occur during boreal spring-summer.
\end{abstract}

Keywords Two types of ENSO $\cdot$ Statistical predictability $\cdot$ Niño indices $\cdot$ Precursors

Jinqing Zuo

zuojq@cma.gov.cn; jqzuo425@126.com

1 Laboratory for Climate Studies and CMA-NJU Joint Laboratory for Climate Prediction Studies, National Climate Center, China Meteorological Administration, Beijing 100081, China

2 Department of Atmospheric Science, School of Environmental Studies, China University of Geoscience, Wuhan 430074, China

3 Collaborative Innovation Center on Forecast and Evaluation of Meteorological Disasters, Nanjing University of Information Science and Technology, Nanjing 210044, China

4 School of Earth and Atmospheric Sciences, Georgia Institute of Technology, Atlanta, GA, USA

\section{Introduction}

The El Niño-Southern Oscillation (ENSO) dominates interannual climate variability in the tropics and has a remarkable impact on the global climate (e.g., Rasmusson and Carpenter 1982; Brönnimann 2007; Zhang et al. 2017). Over the past three decades, much attention has been given to predicting ENSO and such predictions of the ENSO signal have laid a strong foundation for short-term climate predictions. Previous studies focusing on improving ENSO predictions have made significant progress. Overall, the predictive skill for ENSO has been high when using the Niño3.4 sea surface temperature (SST) anomaly index to represent the ENSO phenomenon (Latif et al. 1998; Jin et al. 2008; Luo et al. 2008; Ren et al. 2017); this skill, however, is always relatively lower in real-time forecasts than in hindcasts and varies during epochs with considerable uncertainties (Barnston 
et al. 2012). The recent experiences in predicting 2014-2016 super El Niño event have challenged current capability of international ENSO prediction and given enlightenments for further researches on prediction (Mu and Ren 2017).

Many methods and techniques are being continuously developed to understand atmospheric and oceanic processes key to the formation of ENSO-related SST anomalies and to improve ENSO predictions as a result of progress with respect to ENSO dynamics, climate modeling, and oceanic data assimilation (e.g., Sun et al. 2006; Deng et al. 2012; Park et al. 2012). In general, models for predicting ENSO include simplified dynamical atmosphere-ocean coupled models, fully coupled global climate models, and climate system models, as well as physics-based statistical models (e.g., Zebiak and Cane 1987; Chen et al. 1995; Kang and Kug 2000; Kirtman 2003; Luo et al. 2005; Izumo et al. 2010; Zhang and Gao 2016). All these types of models are used in the monthly routine ENSO forecasting issued jointly by the CPC/NCEP (the Climate Prediction Center/National Centers for Environmental Prediction) and the IRI (the International Research Institute for Climate and Society).

Accompanying the increased understanding of ENSO dynamics, several intermediate atmosphere-ocean coupled models were designed to predict ENSO; such models usually involve simplified atmosphere-ocean coupling and physics with coarse resolutions (Cane et al. 1986; Zebiak and Cane 1987; Chen et al. 1995; Kang and Kug 2000; Zhang et al. 2003) and, being thought to efficiently capture the major dynamics and key physics of ENSO, are still used in operation (Barnston et al. 1999, 2012). Moreover, fully coupled climate models have been widely used to produce ENSO forecasts and have made great progress (Latif et al. 1998; Jin et al. 2008); however, it is always an issue how to accurately initialize these complicated coupled models (Luo et al. 2008; Kirtman and Min 2009). The multi-model ensemble has been proved to be an effective method to improve ENSO predictions (Wang et al. 2009; Kirtman et al. 2014). Meanwhile, due to model deficiencies, post-calibration of ENSO predictions is required via the development of empirical/ statistical correction methods for model forecasts (Kug et al. 2008; Ren et al. 2014; Wang et al. 2017; Liu and Ren 2017).

Because current dynamical models are unrealistic to some degree when depicting ENSO dynamics, statistical ENSO prediction is still an alternative with advantages, such as directly reflecting the intrinsic processes, and external factors that control the variations of ENSO are worthy of being used in operations with a real-time prediction skill comparable to that of dynamical models (Barnston et al. 2012). Many statistical models have been developed and used for ENSO prediction (Xue et al. 2000; Clarke and Van Gorder 2001, 2003; Ruiz et al. 2005; Drosdowsky 2006; Lima et al. 2009; Izumo et al. 2010; Boschat et al. 2013; Tseng et al. 2017). In addition to the initial values of the SST anomaly, the equatorial Pacific warm water volume (WWV) and the surface zonal wind stress (ZWS), which together control the intrinsic dynamics of ENSO, have been widely proved to be effective indicators and the key precursors of the Niño SST indices representing the variations of ENSO (Clarke 2014). The WWV precursor represents the zonally quasi-uniform mode of the tropical Pacific thermocline depth variations, with its peak occurring several months prior to that of the central-eastern Pacific SST anomalies due to the discharge-recharge process of the upper-ocean heat content (Jin 1997a, b; Clarke et al. 2007). The ZWS precursor reflects the contribution of the equatorial zonal wind anomaly, which is phase-locked with the seasonal cycle over the Indo-Pacific areas, to the growth of the SST anomaly in the central-eastern Pacific (Clarke 2014). Other precursors that are located outside the tropical Pacific have also been, or can potentially be, used in ENSO statistical predictions by transferring their signals into ENSO preconditions. Such precursors primarily include the Indian Ocean Dipole (IOD) (Izumo et al. 2010), the North Pacific oscillation (NPO) (Chang et al. 2007; Park et al. 2013), the tropical Atlantic SST anomalies (Ham et al. 2013a, b), and the Southern Hemispheric SST modes (Terray 2011; Boschat et al. 2013). However, further effort is needed to examine the relative roles of these external factors by involving them in "benchmark" statistical prediction models that have previously been established using both the WWV and ZWS precursors.

Despite its considerable successes, ENSO prediction is still a challenging issue with considerable uncertainties, particularly because ENSO behaviors have become increasingly diverse and therefore difficult to predict since around the year 2000 (Barnston et al. 2012). The major factor that caused the decrease in the prediction skill is related to ENSO diversity. A large amount of evidence indicates the coexistence of two flavors/types of ENSO events, the eastern Pacific (EP) type and central Pacific (CP) type, in terms of the zonal positions of their equatorial SST anomaly center, which was likely first noted by Fu et al. (1986). Many studies have revealed that the $\mathrm{CP}$ type has become more frequent since the 1980s (Larkin and Harrison 2005a, b; Ashok et al. 2007; Kao and Yu 2009; Kug et al. 2009; Ren and Jin 2011) and will likely become more frequent in a changed climate (Yeh et al. 2009). The EP and CP types of ENSO, also called the cold-tongue (CT) and warm-pool (WP) types, correspond to two coupled ENSO modes (Bejarano and Jin 2008; Ren et al. 2013; Wang and Ren 2017; Xie and Jin 2018). Because the impact of the CP-type ENSO on the climate worldwide is distinctly different from that of the EP type (e.g., Weng et al. 2007; Kim et al. 2009; Hegyi and Deng 2012; Zhang et al. 2011, 2012; Hegyi et al. 2014; Wang and Wang 2014), large amounts of attention have been given to examining 
the typical features and mechanisms of the two ENSO types (Yeh et al. 2014, and references therein); however, less attention has been given to their predictability.

Recent studies have assessed the performance of dynamical models in predicting the two ENSO types (Hendon et al. 2009; Lim et al. 2009; Jeong et al. 2012, 2015; Yang and Jiang 2014; Imada et al. 2015; Zhu et al. 2015; Ren et al. 2017). These studies show that the EP type has a relatively higher prediction skill than the CP type, even though the latter tends to possess a better persistence or weaker persistence barrier than the former in terms of the Niño indices (Kim et al. 2009; Ren et al. 2016a). It remains unclear whether the CP type is dynamically less predictable than the EP type because current models are not capable of sufficiently reproducing the observed differences in the two ENSO types (Yu and Kim 2010; Ham and Kug 2012). Using an analogue-based correction method for reducing model prediction errors which can be diagnosed from hindcasts at historical analogue states (Ren et al. 2014), forecast skills of the Niño indices representing the two ENSO types can be significantly improved in the CFSv2 predictions (Liu and Ren 2017).

Studies of the statistical predictability of the two ENSO types are necessary, in addition to those based on dynamical models, because many studies have revealed the physical mechanisms for motivation and maintenance of the two ENSO types. Both the equatorial Pacific thermocline and the zonal wind variations play important roles in motivating and maintaining the two ENSO types (Ashok et al. 2007; Ren and Jin 2013), and the recharge oscillator mechanism proposed by Jin (1997a, b) occurs in both ENSO types (Ren and Jin 2013), suggesting that both the WWV and ZWS precursors are expected to be applicable to statistical predictions of the two types of Niño indices. Moreover, some external motivators outside the tropical Pacific could be potential precursors of the two ENSO types (e.g., Boschat et al. 2013; Xie et al. 2013). For example, atmospheric signals from the Pacific subtropics and extratropics tend to trigger the $\mathrm{CP}$ El Niño via the seasonal footprinting mechanism (Yu et al. 2010) and the SST anomalies in the northern tropical Atlantic also favor the CP type (Ham et al. 2013a). Conversely, the equatorial Atlantic SST anomalies tend to enhance the EP type (Ham et al. 2013b; Keenlyside et al. 2013). Recently, a North American dipole (NAD) mode was shown to serve as a unique precursor of a CP El Niño (Ding et al. 2017). Until now, it is still lack of comprehensive examining of statistical predictability of the two ENSO types and hence developing specifically effective statistical models for their respective Niño indices. It also remains unclear whether and to how large a degree these predictors can contribute to the statistical predictability in terms of the two ENSO types because some of these precursors are not generally suitable to ENSO prediction but are strongly locked to the seasonal cycle.
In this study, we focus on the development of statistical prediction models for the different Niño indices that represent the two types of ENSO and examine the statistical predictability of these two types. To do this, we quantitatively demonstrate the relative importance of the key precursors that have been suggested in previous studies with different definitions and then set up an advanced statistical model with relatively high prediction skill for the respective Niño indices of the two ENSO types. Following the introduction, the data and methods are introduced in Sect. 2. The benchmark models for statistically predicting the different Niño indices are set up in Sect. 3. The statistical predictabilities of the two ENSO types are examined in Sect. 4 by incorporating the external precursors into the benchmark models. The establishment and evaluations of the eventual statistical prediction models for the Niño indices of the two ENSO types are given in Sect. 5. A discussion and summary are given in Sect. 6.

\section{Data and methods}

Traditional Niño3.4, Niño3, and Niño4 indices are calculated as SST anomalies averaged over the Niño3.4 $\left(5^{\circ} \mathrm{S}-5^{\circ} \mathrm{N}\right.$, $\left.170^{\circ}-120^{\circ} \mathrm{W}\right)$, Niño3 $\left(5^{\circ} \mathrm{S}-5^{\circ} \mathrm{N}, 150^{\circ}-90^{\circ} \mathrm{W}\right)$, and Niño4 $\left(5^{\circ} \mathrm{S}-5^{\circ} \mathrm{N}, 160^{\circ} \mathrm{E}-150^{\circ} \mathrm{W}\right)$ regions, respectively. The Niño warm-pool index (WPI) and the Niño cold-tongue index (CTI) proposed by Ren and Jin (2011) are used in this study to represent the CP and EP types of ENSO, respectively. We also use the El Niño Modoki index (EMI) of Ashok et al. (2007) for comparison. In this study, the EP-type ENSO indices include both the CTI and the Niño3 index, and the CP-type indices include the WPI, EMI as well as the Niño4 index. Definitions of these SST-based indices are given in Table 1. All indices are calculated using monthly optimum interpolation SST (OISST) data from the National Oceanic and Atmospheric Administration (Reynolds et al. 2002), which have a horizontal resolution of $1^{\circ} \times 1^{\circ}$.

We use the monthly potential temperature and the zonal momentum flux (zonal wind stress) from the NCEP Global Ocean Data Assimilation System (Behringer and Xue 2004; Huang et al. 2008). These datasets have a horizontal resolution of $0.333^{\circ}$ in latitude and $1.0^{\circ}$ in longitude. The WWV is represented by the $20^{\circ} \mathrm{C}$ isotherm depth. Monthly global atmospheric circulation data are derived from the NCEP/ National Center for Atmospheric Research Reanalysis data, which have a horizontal resolution of $2.5^{\circ} \times 2.5^{\circ}$ (Kalnay et al. 1996). The study is conducted during the period of 1982-2016, when all these datasets were available. Monthly anomalies are calculated relative to the climatology of the entire period, and a 3-month running average is applied to the data to reduce the noise. Linear trends were removed prior to the analysis. 
Table 1 Definitions of the Niño indices and their precursors from the tropical Indian and Atlantic oceans and the extratropics

\begin{tabular}{|c|c|c|}
\hline Indices & Definitions & References \\
\hline Niño3 & $\operatorname{SST}\left(15^{\circ}-90^{\circ} \mathrm{W}, 5^{\circ} \mathrm{S}-5^{\circ} \mathrm{N}\right)$ & Trenberth and Stepaniak (2001) \\
\hline Niño4 & $\operatorname{SST}\left(160^{\circ} \mathrm{E}-150^{\circ} \mathrm{W}, 5^{\circ} \mathrm{S}-5^{\circ} \mathrm{N}\right)$ & \\
\hline Niño3.4 & $\operatorname{SST}\left(170^{\circ}-120^{\circ} \mathrm{W}, 5^{\circ} \mathrm{S}-5^{\circ} \mathrm{N}\right)$ & \\
\hline CTI & Niño3 $-\alpha$ Niño4 & Ren and Jin (2011) \\
\hline WPI & Niño4- $\alpha$ Niño3 & \\
\hline EMI & $\begin{array}{l}\mathrm{SST}\left(165^{\circ} \mathrm{E}-140^{\circ} \mathrm{W}, 10^{\circ} \mathrm{S}-10^{\circ} \mathrm{N}\right)-\mathrm{SST}\left(110^{\circ}-70^{\circ} \mathrm{W}, 15^{\circ} \mathrm{S}-5^{\circ} \mathrm{N}\right) / 2-\mathrm{SST}\left(125^{\circ}-\right. \\
\left.145^{\circ} \mathrm{E}, 10^{\circ} \mathrm{S}-20^{\circ} \mathrm{N}\right) / 2\end{array}$ & Ashok et al. (2007) \\
\hline IOD & $\operatorname{SST}\left(50^{\circ}-70^{\circ} \mathrm{E}, 10^{\circ} \mathrm{S}-10^{\circ} \mathrm{N}\right)-\mathrm{SST}\left(90^{\circ}-110^{\circ} \mathrm{E}, 10^{\circ} \mathrm{S}-\mathrm{EQ}\right)$ & Saji et al. (1999) \\
\hline NTA & $\operatorname{SST}\left(\mathrm{EQ}-15^{\circ} \mathrm{N}, 90^{\circ} \mathrm{W}-20^{\circ} \mathrm{E}\right)$ & Ham et al. (2013) \\
\hline SIOD & $\operatorname{SST}\left(30^{\circ}-50^{\circ} \mathrm{S}, 35^{\circ}-75^{\circ} \mathrm{E}\right)-\mathrm{SST}\left(15^{\circ}-48^{\circ} \mathrm{S}, 80^{\circ}-120^{\circ} \mathrm{E}\right)$ & Terray (2011); Boschat et al. (2013) \\
\hline SAOD & $\mathrm{SST}\left(30^{\circ}-50^{\circ} \mathrm{S}, 50^{\circ} \mathrm{W}-20^{\circ} \mathrm{E}\right)-\mathrm{SST}\left(10^{\circ}-30^{\circ} \mathrm{S}, 50^{\circ} \mathrm{W}-20^{\circ} \mathrm{E}\right)$ & \\
\hline NAD & $\operatorname{SLP}\left(9^{\circ}-29^{\circ} \mathrm{N}, 58^{\circ}-93^{\circ} \mathrm{W}\right)-\operatorname{SLP}\left(53^{\circ}-68^{\circ} \mathrm{N}, 43^{\circ}-77^{\circ} \mathrm{W}\right)$ & Ding et al. (2017) \\
\hline NPO & $\operatorname{SLP}\left(50^{\circ}-71^{\circ} \mathrm{N}, 175^{\circ}-120^{\circ} \mathrm{W}\right)-\operatorname{SLP}\left(8^{\circ}-26^{\circ} \mathrm{N}, 179^{\circ} \mathrm{E}-139^{\circ} \mathrm{W}\right)$ & \\
\hline
\end{tabular}

Note that $\alpha=0.4$ when Niño3 $\times$ Niño $4>0$, and otherwise, $\alpha=0$

SST and SLP denote the sea surface temperature and sea level pressure, respectively

The prediction skills of the Niño indices are evaluated using the temporal correlation coefficients (TCCs) between the observations and the predictions. Both the leave-oneout cross validation and the independent validation are used to assess the statistical predictabilities of the Niño indices. For the independent validation, the prediction is performed during the period of 1997-2016 using observations for the period from 1982 to the target year. Because the skill scores obtained from the cross validation are very similar to those obtained from the independent validation, we only show the results of the cross validation. The statistical significance of the regression coefficient and the correlation coefficient is assessed using a two-tailed Student's $t$ test, and the difference between two correlation coefficients is tested using the Steiger's $z$ test (Meng et al. 1992).

\section{Benchmark models using the equatorial Pacific heat content and zonal wind stress}

\subsection{Relationships of the Niño indices with the heat content and zonal wind stress}

In previous statistical models that did not consider the two ENSO types, the equatorial Pacific upper-ocean heat content (i.e., the WWV) and the ZWS precursors have been widely used. Due to their importance in the ENSO evolution, Figs. 1 and 2 examine the lead-lag correlations of different Niño indices with the equatorial $\left(5^{\circ} \mathrm{S}-5^{\circ} \mathrm{N}\right) \mathrm{WWV}$ and $\mathrm{ZWS}$ anomalies, respectively. It is clearly seen in Fig. 1 that significant WWV signals appear in nearly the entire equatorial Pacific prior to the SST peak, and in particular, the zonally quasi-uniform WWV signal leads the SST peak by more than half a year for all the Niño indices. It is noteworthy that the WWV signal associated with the EP-type indices (Fig. 1a-b) is centered more eastward compared to that for the CP-type indices (Fig. 1d-f). Moreover, the lag relationships of the WPI and EMI with the equatorial Pacific WWV anomalies are obviously weaker compared to those for the other Niño indices.

In Fig. 2, the most significant positive ZWS anomalies are observed over the equatorial central-western Pacific leading the SST peak by up to 10 months for all the Niño indices. In addition, note that remarkably negative ZWS anomaly signals appear in the equatorial eastern Pacific prior to the CP ENSO peak, whereas prior to the EP ENSO peak, there are much weaker signals there as well as apparent signals in the equatorial eastern Indian Ocean. Overall, the lead time of the ZWS signal with respect to the SST signal is relatively shorter than that of the WWV signal for both the EP and CP ENSO indices, and the lag correlation of the Niño3.4 index with both the WWV and ZWS precursors is relatively high compared to the other Niño indices.

\subsection{Benchmark models and prediction skills for different Niño indices}

In this study, we first build benchmark models that use only the initial values of the Niño indices and the equatorial Pacific WWV and ZWS as precursors. Here, we give a multi-element linear regression equation to represent the benchmark model:

$\operatorname{Niño}(t)=\alpha \operatorname{Niño}(t)+\beta \operatorname{WWV}(t)+\gamma \mathrm{ZWS}(t)$,

where $\alpha, \beta$, and $\gamma$ are parameters that change with calendar month and lead month, and can be obtained by applying a 


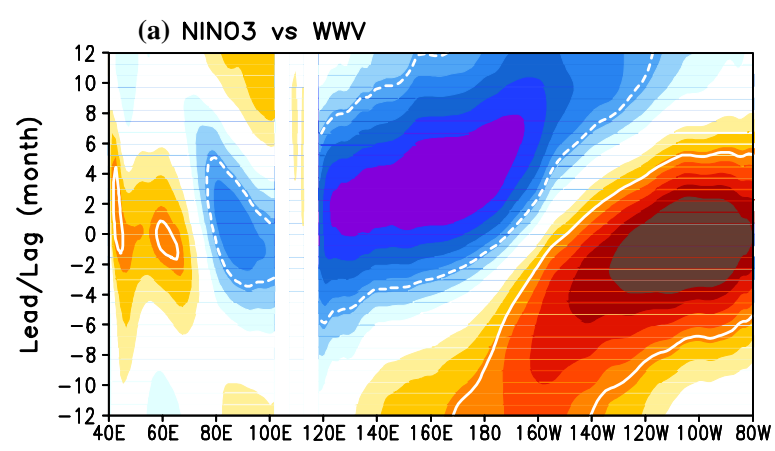

(b) CT vs WWV

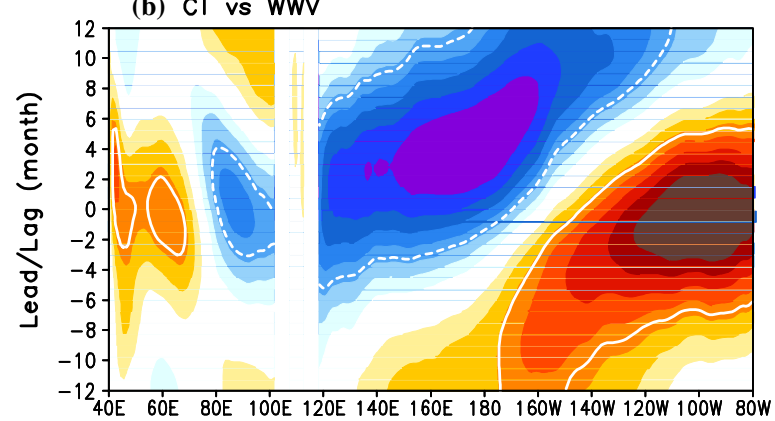

(c) NINO34 vs WWV

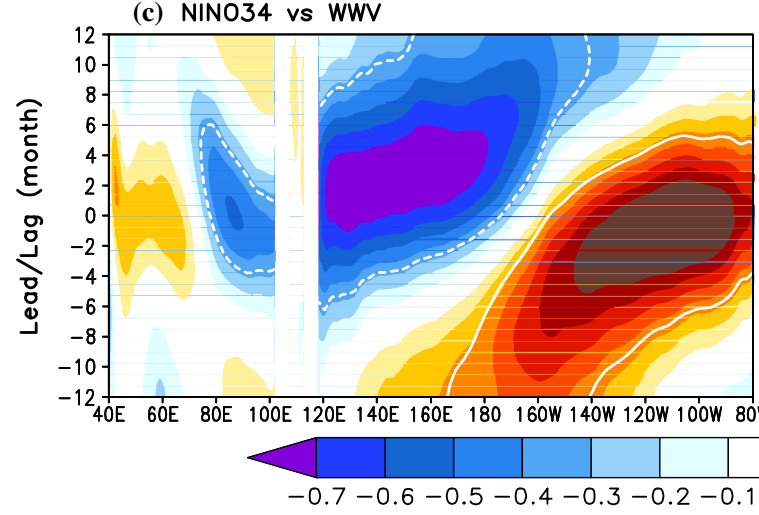

Fig. 1 Lead-lag correlations between the a Niño3, b CT, c Niño3.4, d Niño4, e WP, and $\mathbf{f}$ EMI indices and the equatorial $\left(5^{\circ} \mathrm{S}-5^{\circ} \mathrm{N}\right)$ mean depth of the $20^{\circ} \mathrm{C}$ isotherm (WWV) for all months combined dur-

linear fit to the observations, $t$ denotes the target month for the prediction, and $\tau$ denotes the initial month.

For the model of each Niño index, the definitions of the WWV and ZWS indices refer to the correlation domains shown in Figs. 1 and 2. Table 2 lists the spatial domains used to define the WWV and ZWS indices as precursors for the different Niño indices, which are generally grouped for the EP and CP ENSO types. According to the results shown in Fig. 2, the ZWS anomalies in both the equatorial central-western and eastern Pacific are combined to define the precursors in the models of the CP ENSO indices, whereas only those in the equatorial central-western Pacific are used to define the precursors of the EP ENSO indices. Additional attempts were made to define the WWV and ZWS indices by changing the zonal range of the domains, and for each

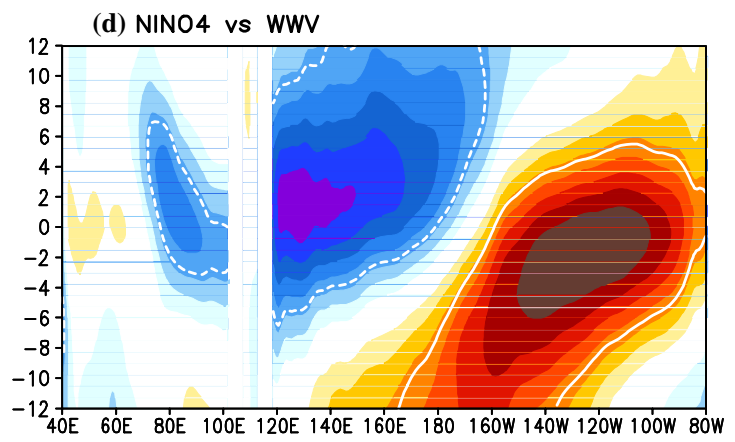

(e) WP VS WWV

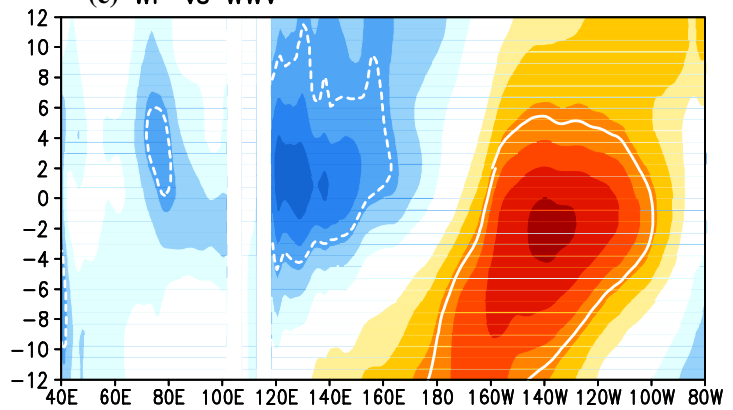

(f) EMI vs WWV

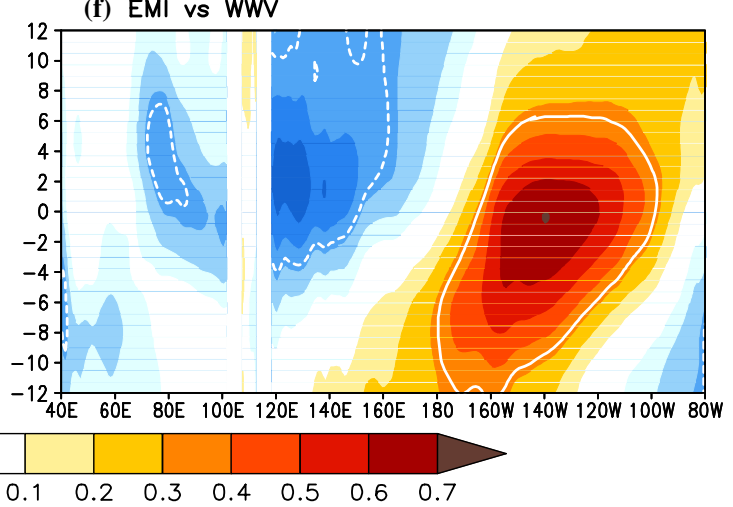

ing the period of 1982-2016. White contours indicate significance at $95 \%$ confidence level. Lead times with negative values indicate that the WWV is leading

Niño index, we have chosen the domains that offer the best prediction of that Niño index. Note that the definition of the WWV index for the CP type is slightly different from that for the EP type, while the definitions of the ZWS index differ significantly for the two types.

As Clarke and Van Gorder (2003) revealed, the westerly (easterly) wind anomalies, which are phase-locked to the seasonal cycle, usually propagate from the equatorial eastern Indian Ocean into the western Pacific with the development of an El Niño (La Niña) event. They demonstrated that a space-time integration of the Indo-Pacific ZWS signal could improve the prediction skill of the Niño3.4 index for some leads in the range of 10-15 months. However, we did not find an apparent improvement in the prediction of the Niño indices for leads in the range of $0-11$ months 


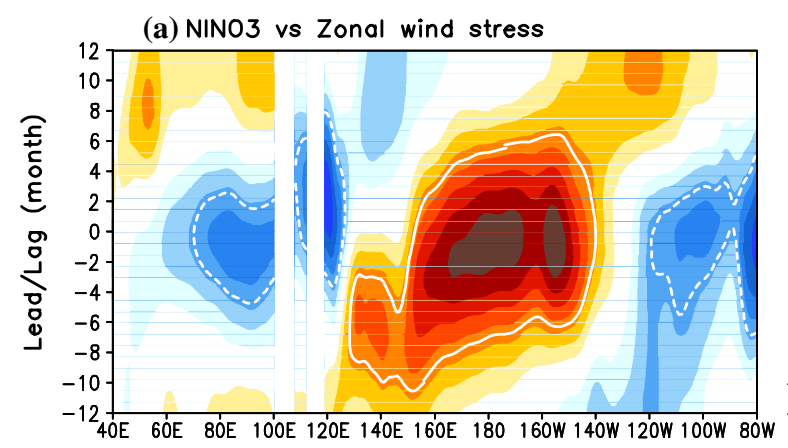

(b) CT vs Zonal wind stress

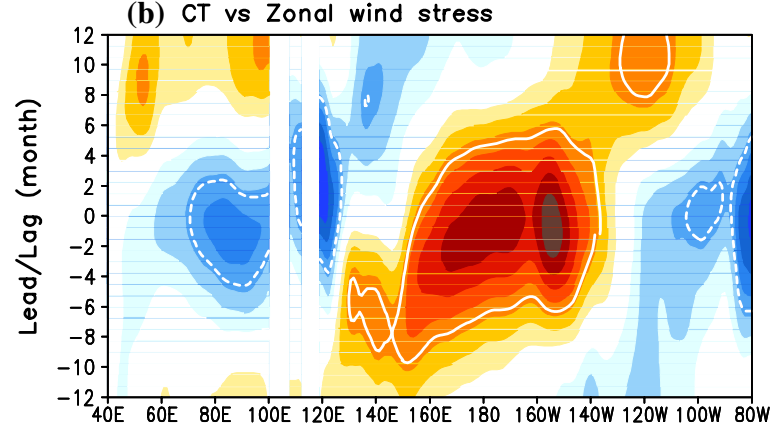

(c) NINO34 vs Zonal wind stress

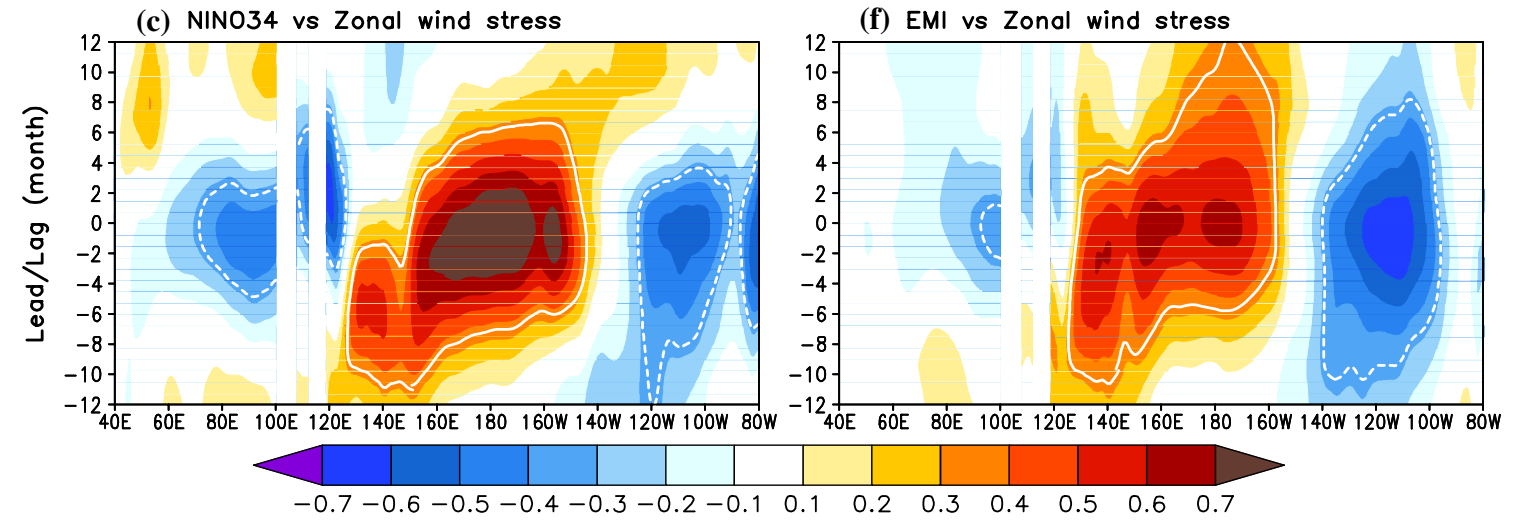

(d) NINO4 vs Zonal wind stress

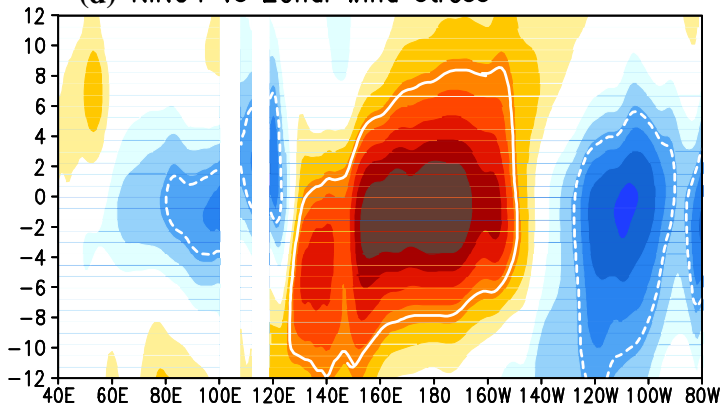

(e) WP vs Zonal wind stress

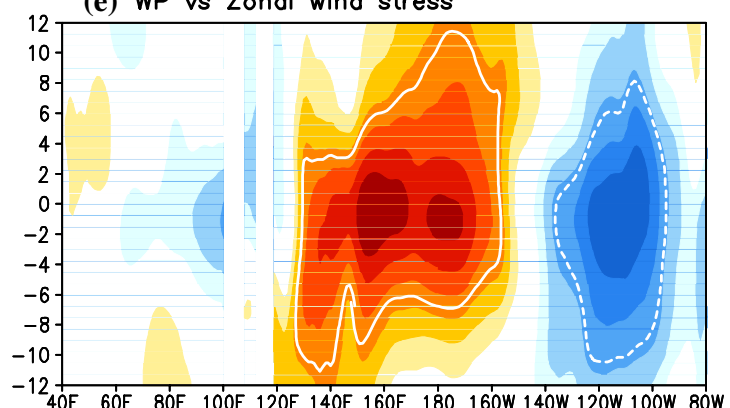

(f) EMI vs Zonal wind stress

Fig. 2 The same as Fig. 1, but for correlations with the equatorial $\left(5^{\circ} \mathrm{S}-5^{\circ} \mathrm{N}\right)$ zonal wind stress (ZWS) anomalies

Table 2 Domains used to calculate the WWV and ZWS precursors for each Niño index

\begin{tabular}{lll}
\hline & WWV & ZWS \\
\hline Niño3, CTI and Niño3.4 & $130^{\circ} \mathrm{E}-80^{\circ} \mathrm{W}, 5^{\circ} \mathrm{S}-5^{\circ} \mathrm{N}$ & $130^{\circ} \mathrm{E}-150^{\circ} \mathrm{W}, 5^{\circ} \mathrm{S}-5^{\circ} \mathrm{N}$ \\
Niño4, WPI and EMI & $130^{\circ} \mathrm{E}-100^{\circ} \mathrm{W}, 5^{\circ} \mathrm{S}-5^{\circ} \mathrm{N}$ & $\left(125^{\circ} \mathrm{E}-160^{\circ} \mathrm{W}, 5^{\circ} \mathrm{S}-\right.$ \\
& & $\left.5^{\circ} \mathrm{N}\right)-\left(125^{\circ} \mathrm{W}-100^{\circ} \mathrm{W}\right.$, \\
& & $\left.5^{\circ} \mathrm{S}-5^{\circ} \mathrm{N}\right)$ \\
\hline
\end{tabular}

using a scheme involving both the equatorial Indian and Pacific ZWS signals compared to our scheme, which considers only the equatorial Pacific ZWS (figures omitted). This result reflects the fact that both the EP and CP ENSO indices have major correlations with the simultaneous or short-lead ZWS signals in the equatorial Indian Ocean (Fig. 2). Therefore, only the equatorial Pacific ZWS signals are used in our benchmark models.
To evaluate the prediction skill of the benchmark model, the cross-validated TCC skill scores of the Niño indices predicted by the benchmark model and their differences relative to the persistence forecast for all the months combined during the period of 1982-2016 are computed, as shown in Fig. 3. It is indicated that the skill scores of the benchmark model feature a gradual decline with increasing lead months for all the Niño indices (Fig. 3a). Compared to the 
(a) TCC skills

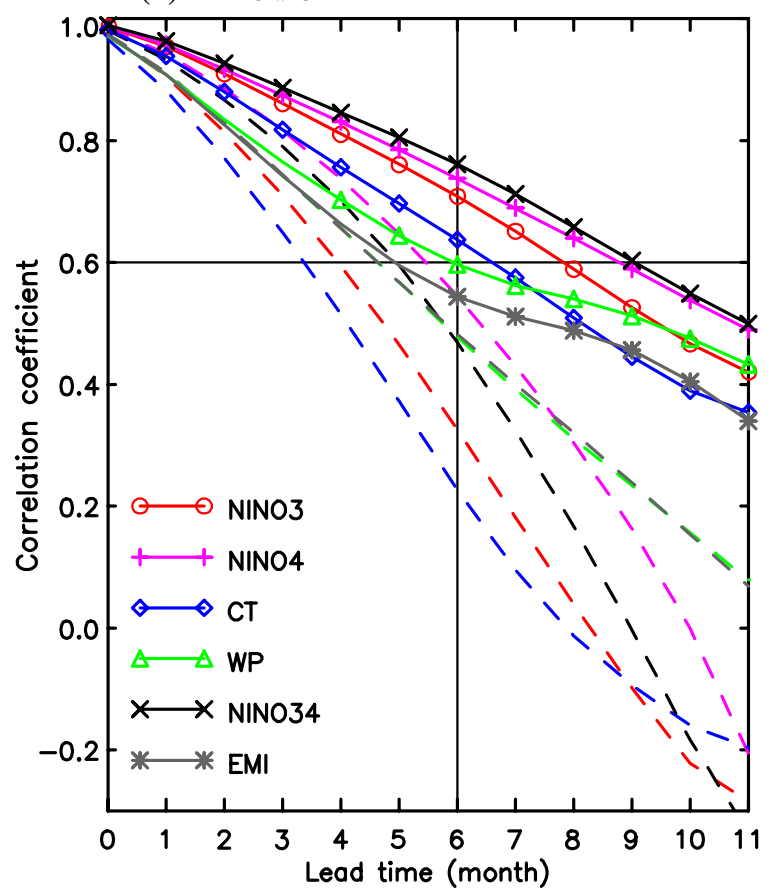

Fig. 3 a Cross-validated correlation skill scores (solid line) of the Niño indices predicted by the benchmark model and $\mathbf{b}$ their differences relative to the persistence forecast (dashed line in panel a) for

skill scores of persistence forecast, the WWV and ZWS precursors can significantly contribute to the skills of the CTI and the Niño3, Niño4 and Niño3.4 indices for leads of 1-11 months (Fig. 3b). For the EMI (WPI), its skill in the benchmark model is much higher than that of the persistence forecast for leads longer than 6 (4) months. Note that the Niño3.4 index has the highest skill and that the Niño4 index has a slightly higher skill than the Niño3 index. Moreover, both the CTI and the WPI, defined as a transformation of the Niño3 and Niño4 indices (Ren and Jin 2011), show relatively lower skills compared to the latter two, respectively. This may be due to their definitions, which use the differences of the two domain-averaged Niño indices, and is consistent with the results shown in Figs. 1 and 2, where the correlations for the Niño3 and Niño4 indices are for the most part higher than those for the CTI and WPI.

We further examine the dependence of the skills of the benchmark models on the target calendar months, as shown in Fig. 4. The cross-validated skill scores (see the contours) of the three Niño indices that are usually used to represent the traditional or EP ENSO are higher during boreal autumn and winter but much lower during spring and summer (Fig. 4a-c), whereas those of the CP ENSO indices appear to be higher during winter and spring but lower during late summer and autumn (Fig. $4 \mathrm{~d}-\mathrm{f}$ ). This is one of the most significant features in the differences of the statistical (b) Difference of skills

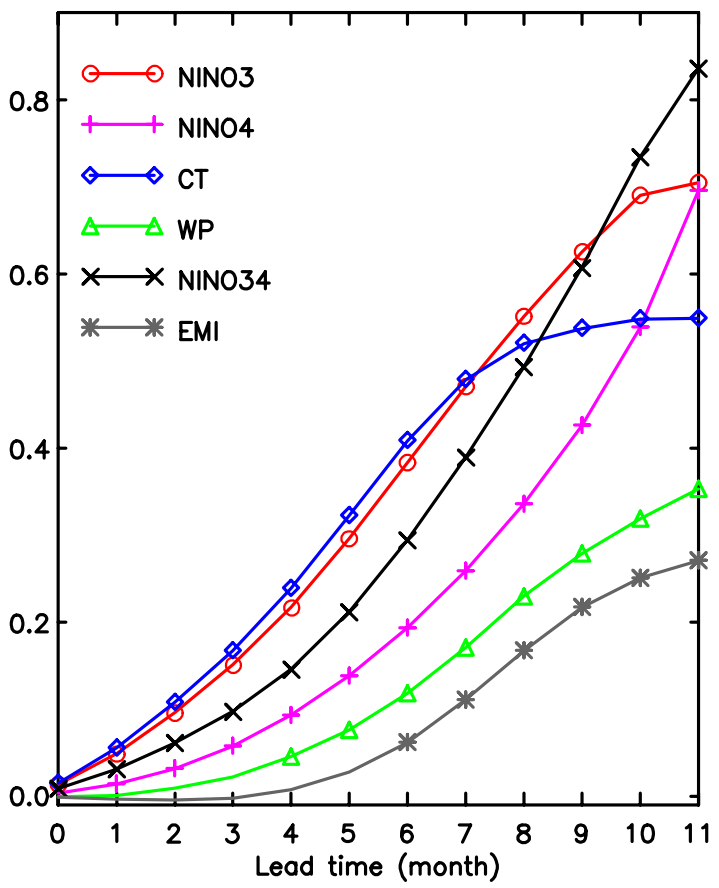

all months combined during the period of 1982-2016. Markers indicate that the difference is significant at the $95 \%$ confidence level

predictability between the two ENSO types. In Fig. 4c, the skill pattern of the Niño3.4 index is similar to those in previous studies (e.g., Barnston et al. 2012). It is clear that the predictions of the CTI and the Niño3 and Niño3.4 indices have a higher skill score for most of the target and lead months, except the target months of January-April with short leads, compared to those of the persistence forecast. However, the predictions of the CP-type indices are less skillful in the benchmark model than those of the EP-type indices for some of the target and lead months. In particular, the EMI only has superior skill scores in the boreal autumn and winter with long leads in the model, compared to the persistence forecast.

Figure 4 indicates that the WWV and ZWS precursors in the benchmark models can significantly contribute to the prediction skills of most of the Niño indices with leads longer than $~ 1(6)$ month(s) for target months during the period of June-December (January-February). A useful skill score (of more than 0.6) can be obtained across the spring predictability barrier (SPB) where the prediction skills decline most rapidly. The SPB is closely related to the persistence barrier of ENSO, which usually occurs in late spring to early summer (Ren et al. 2016a), as shown in Fig. 5. In the study of Ren et al., the persistence barrier is quantitatively shown to be distinct for the EP and CP types of ENSO; the persistence barrier tends to occur in 


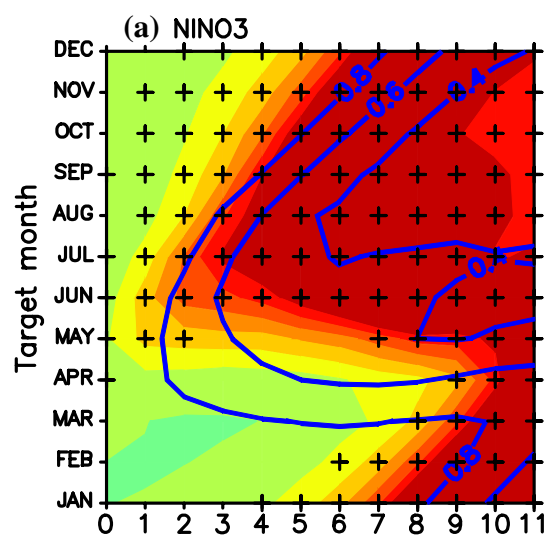

(d) $\mathrm{NINO} 4$

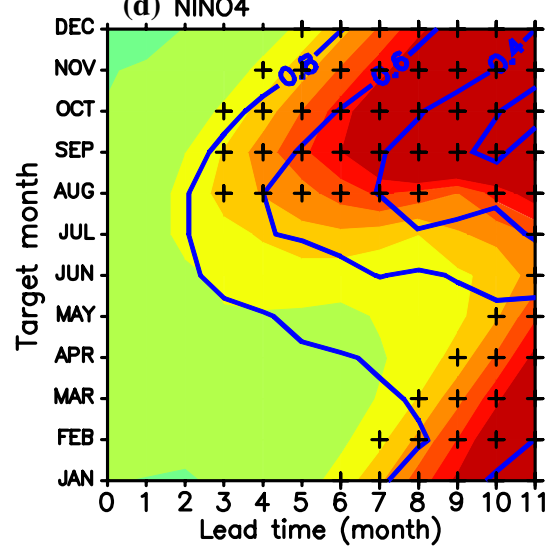

dime (b) $\mathrm{CT}$

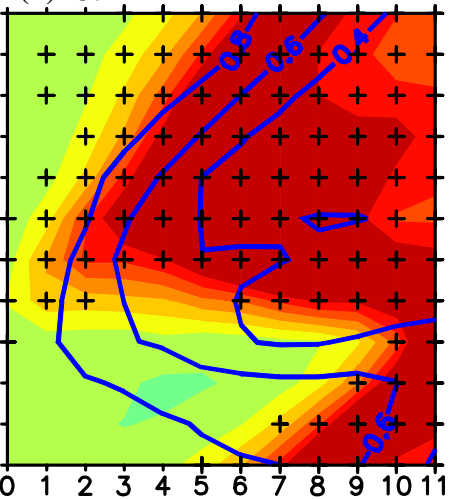

(e) WP

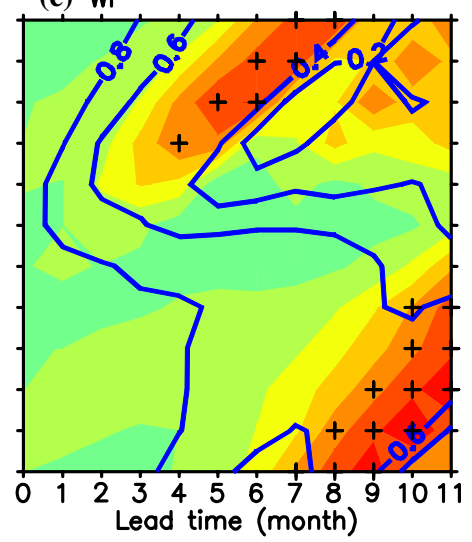

(c) NINO34

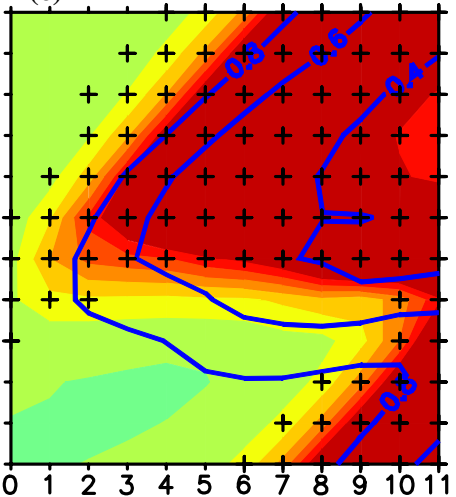

(f) $\mathrm{EMI}$

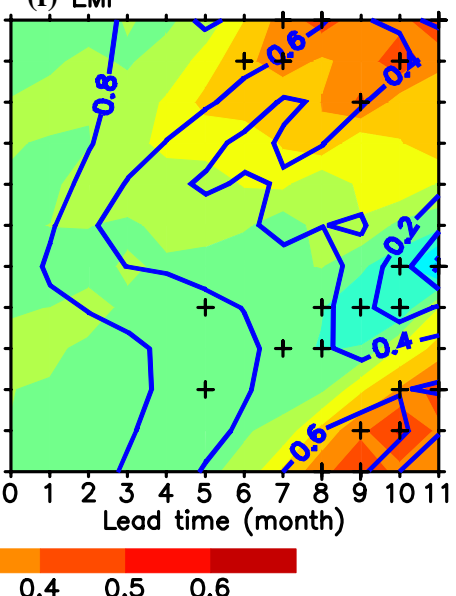

Fig. 4 Cross-validated correlation skill scores (contours) as a function of target calendar month ( $y$ axis) and lead month ( $x$ axis) for the benchmark model and their differences (shading) relative to the per- sistence forecast for the a Niño3, b CT, c Niño3.4, d Niño4, e WP, and $\mathbf{f}$ EMI indices during the period of 1982-2016. Crosses indicate that the difference is significant at the $95 \%$ confidence level late spring with a stronger intensity for the EP type and in summer with a weaker intensity for the CP type (see the shading in Fig. 6). Based on Fig. 4, similar conclusions can be obtained for the SPB. Here, we can examine the timings and intensity of the SPB by identifying the maximum decline rate of the prediction skills using a method similar to the definition of the ENSO persistence barrier (Ren et al. 2016a). It is shown that the SPB of the EP type appears to be earlier and stronger compared to that of the CP type (see the contours in Fig. 6). In fact, the predictability barrier of the EP type typically occurs during boreal spring, whereas that of the CP type tends to be more visible during boreal summer. It is also clear that the evident skill superiority provided by the WWV and ZWS precursors, compared to the persistence forecast, primarily occurs during the SPB and afterwards. However, the prediction skills for the CP ENSO indices have much less skill superiority, partly due to their own better persistence (Ren et al. 2016a). Indeed, involving new precursors outside the tropical Pacific is likely a potential way to further improve the CP ENSO prediction.

\section{Predictability from other precursors in the tropics and extratropics}

\subsection{Contributions to the prediction skills of Niño indices}

Previous studies have demonstrated that there are several external signals from outside the tropical Pacific that can lead the ENSO peak (Ding et al. 2017 and references therein). Impacts of these external signals on the prediction skills of the Niño indices are examined here. The examined precursors include the IOD in Sept-Oct-Nov (SON), the northern tropical Atlantic (NTA) SST anomalies in Feb-Mar-Apr (FMA), the southern Indian Ocean Dipole (SIOD) in FMA, the southern Atlantic Ocean Dipole (SAOD) in FMA, and the NAD and NPO in Nov-Dec-Jan (NDJ), which have been demonstrated to have an important impact on the ENSO variability (Izumo et al. 2010; Boschat et al. 2013; Ham et al. 2013a, b; Ding et al. 2017). Definitions of these precursors are given in Table 1, where the IOD, NTA, SIOD, and SAOD indices are defined using 
(a) NINO3

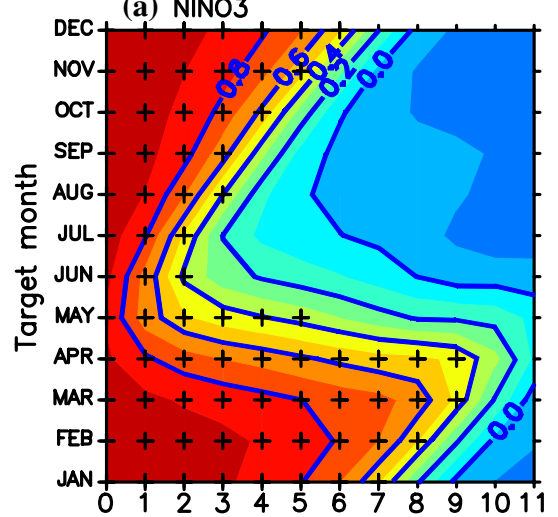

(d) NINO4

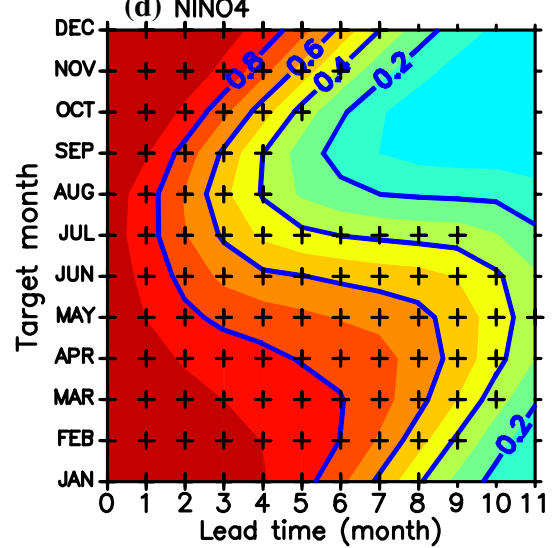

(b) CT

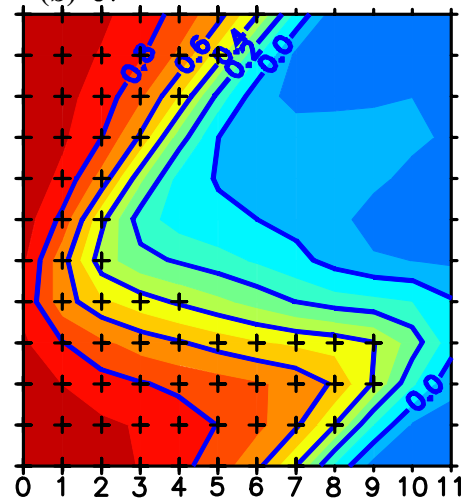

(e) WP

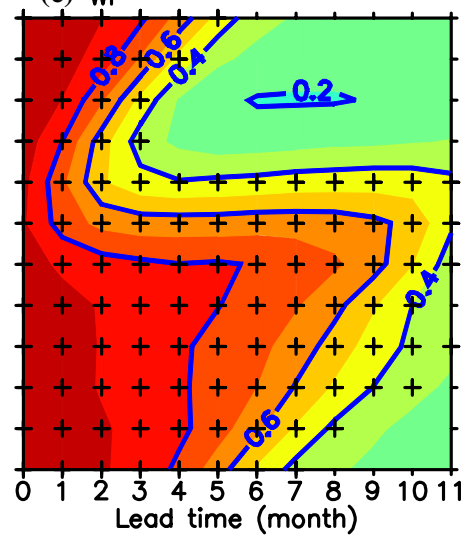

(c) NINO34

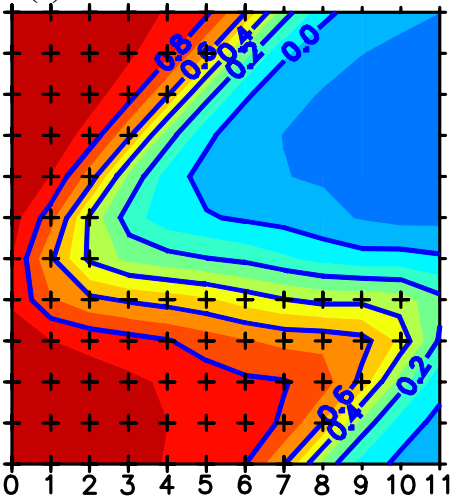

(f) EMI

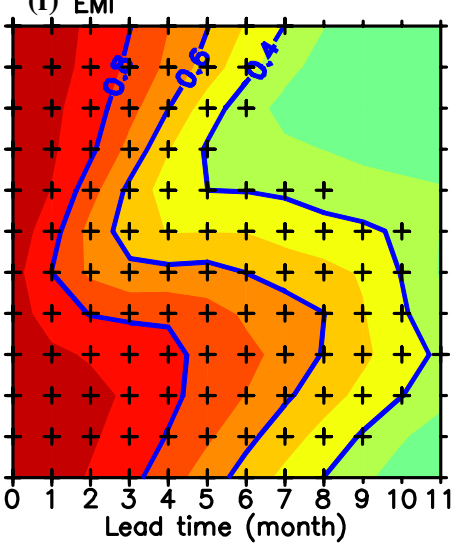

$$
\begin{array}{llllllllllll}
-0.2 & -0.1 & 0 & 0.1 & 0.2 & 0.3 & 0.4 & 0.5 & 0.6 & 0.7 & 0.8 & 0.9
\end{array}
$$

Fig. 5 Autocorrelations of the a Niño3, b CT, $\mathbf{c}$ Niño3.4, d Niño4, e WP, and $\mathbf{f}$ EMI indices during the period of 1982-2016. Crosses indicate significance at the $95 \%$ confidence level

SST anomalies while the NAD and NPO indices are defined using sea level pressure (SLP) anomalies.

These selected precursors have distinct ways to affect ENSO, as referred to these aforementioned papers. The IOD related signal in SON can influence the sequent winter ENSO in phase and the second sequent winter ENSO out of phase through exciting the surface westerly wind anomalies over the western Pacific and then the ocean dynamics (Izumo et al. 2010). The NTA SST cooling in FMA contributes to the $\mathrm{CP}$ warming at the sequent winter via the air-sea interaction over the tropical Pacific (Ham et al. 2013a). The NAD in NDJ, as an atmospheric signal, can induce SST anomalies in the NTA and then subsequently influence the development of the CP El Niño (Ding et al. 2017). The NPO-related atmospheric signals from the Pacific subtropics and extratropics tend to trigger the CP El Niño via the seasonal footprinting mechanism (Chang et al. 2007; Park et al. 2013). The SIOD and SAOD in FMA both can affect ENSO development by modulating the southeast trades over the South Pacific in spring (Terray 2011; Boschat et al. 2013).

To investigate the impact of precursors from outside the tropical Pacific on the prediction skills of the Niño indices, the benchmark skill score is first obtained from a benchmark model built with the WWV and ZWS precursors and then the TCC skill scores are calculated for each Niño index by individually adding other precursor (e.g., IOD) to the benchmark model. Figure 7 shows the lag correlations of the Niño indices with the aforementioned precursors at a given season from which the impacts of Niño3.4 SST signal in the previous Dec-Jan-Feb (DJF) season have been linearly removed by using a regression, and Fig. 8 displays cross-validated TCC skill scores for the Niño indices predicted by individually adding these precursors into the benchmark model and their differences relative to the benchmark skills. Note that the IOD and other precursors are used at all initial months as predictors in the statistical models and not just locked to certain seasons as discussed previously.

Figure 7a demonstrates that the Niño3.4 index has a significant in-phase relationship with the SON IOD index for short lags but an out-of-phase relationship for long lags, with a maximum correlation at a lag of $\sim 15$ months. This agrees well with Izumo et al. (2010), who revealed that a negative (positive) phase of the SON IOD leads the El Niño (La Niña) peak by approximately 14 months. Similar results 
(a) NINO3

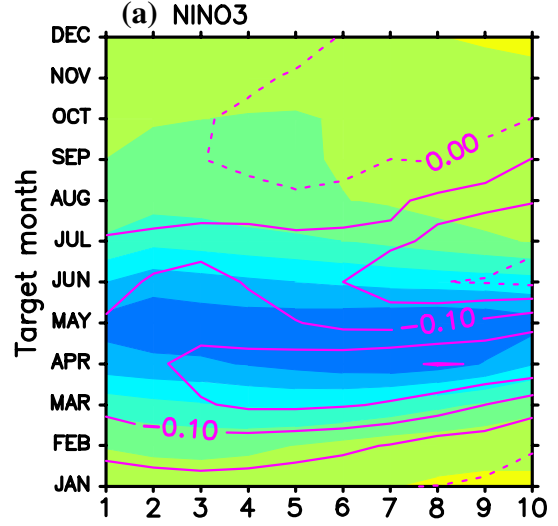

(d) NINO4

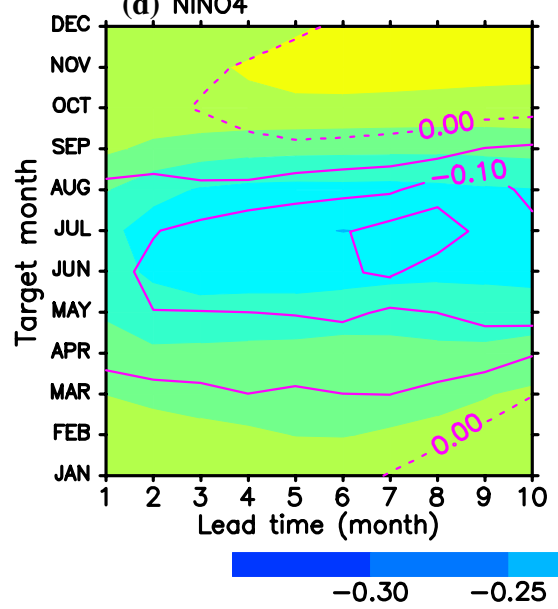

(b) CT

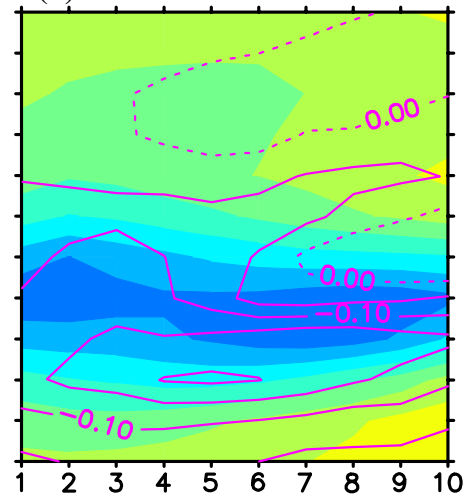

(e) WP

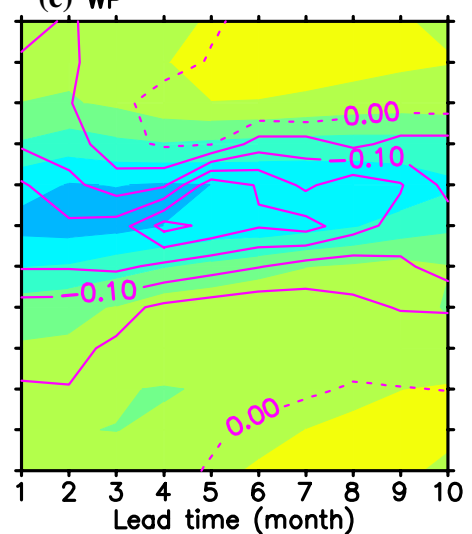

(c) NINO34

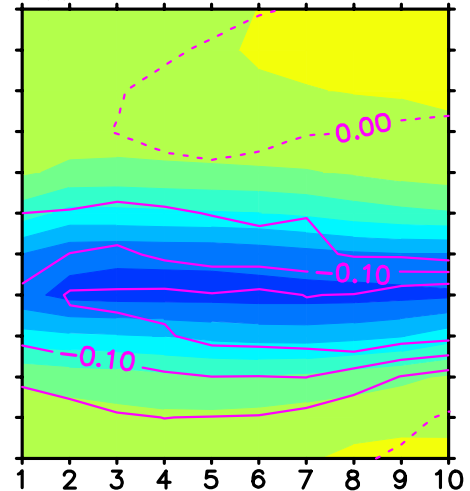

(f) EMI

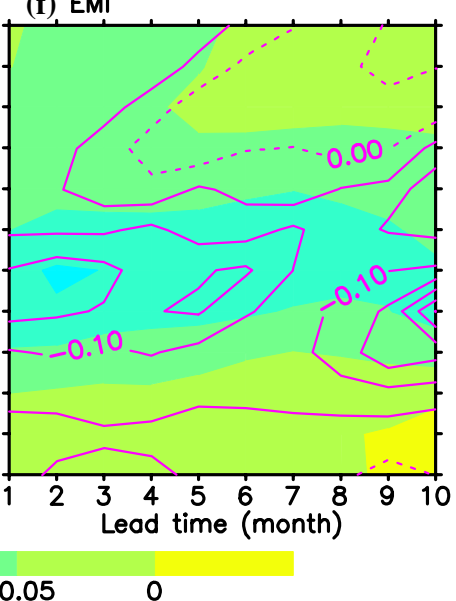

Fig. 6 Decline rate of the autocorrelations (shading) and cross-validated correlation skill scores for the benchmark model (contours) of the a Niño3, b CT, $\mathbf{c}$ Niño3.4, d Niño4, e WP, and $\mathbf{f}$ EMI indices during the period of 1982-2016. Contours with negative values are solid

of a lag relationship are obtained for the CTI and the Niño3 and Niño4 indices; however, a relatively weak and still significant correlation is found between the WPI and the SON IOD index. As expected, the TCC skill scores of the Niño indices, except WPI, are improved by introducing the IOD signal when the predictions are initiated during the boreal autumn and this limited improvement is not significant and is only visible after 4-5 forecast months (Fig. 8a-e).

The NTA SST anomalies during the boreal spring (FMA) could be a candidate predictor of the CP ENSO (Ham et al. $2013 \mathrm{a}, \mathrm{b})$. This is supported by Fig. 7b, which indicates that the NTA index in FMA has a significant and negative correlation with both the WPI and the Niño4 index in the following months, with a maximum correlation for a lead of $\sim 10$ months. Consistently, significant improvements are observed in the boreal autumn-winter predictions of WPI when starting from January-February (Fig. 8i), while similar but relatively weak improvements are found for the Niño4 index (Fig. 8h). Conversely, the correlations of the NTA index in FMA with the CTI and the Niño3 index in the following months are relatively weak (Fig. 7b); therefore, the impact of the former on the skill scores of the two EP ENSO indices is also weak (Fig. 8f, g). However, note that the NTA precursor during the late summer-early autumn can significantly improve the predictions of the EP ENSO indices, as well as the Niño3.4 index, as opposed to the CP ENSO indices, as seen in Fig. 8f, g, j. Such a distinct impact of the boreal spring and summer-autumn NTA SST anomalies on the two types of ENSO may be related to the seasonal evolutions of the mean state (Rodríguez-Fonseca et al. 2009; Ham et al. 2013a, b), which requires further examination but lies beyond the scope of the present study.

The subtropical dipole-like SST variability in the southern Indian and Atlantic oceans may provide another source of predictability for ENSO during recent decades (Terray 2011; Boschat et al. 2013). Here, we define the SST-based SIOD and SAOD indices, where the spatial domains are determined following Terray (2011) and Boschat et al. (2013). The SIOD index in FMA is significantly and positively correlated with the CTI and the Niño3 and Niño3.4 indices when the former leads over a range of 1-14 months (Fig. 7c), and similar correlation patterns are observed for the SAOD index in FMA with even higher correlations (Fig. 7d). Both the SIOD and SAOD indices in FMA have 
(a) SON IOD

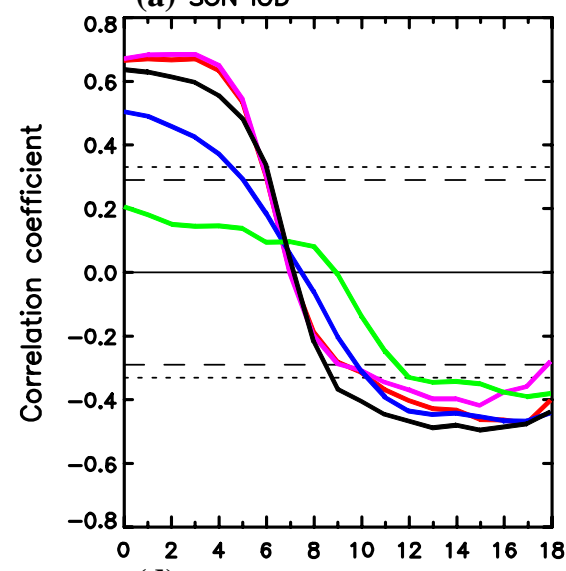

(d) FMA SAOD

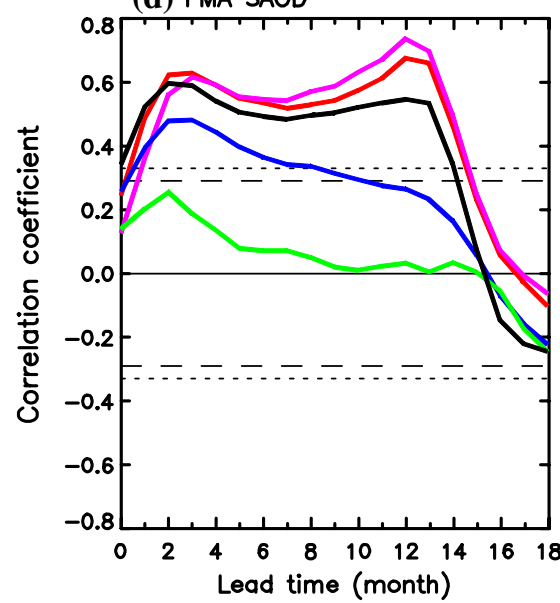

(b) FMA NTA

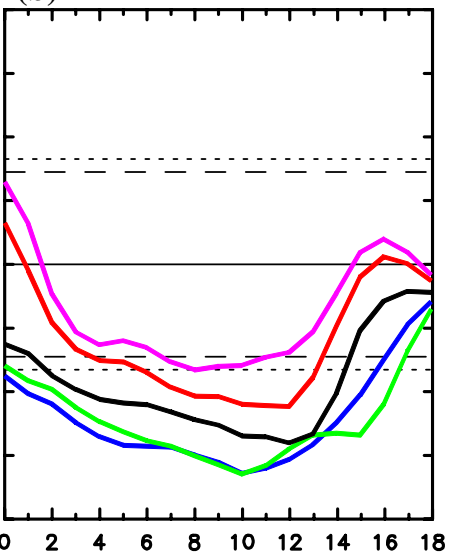

(e) NDJ NAD

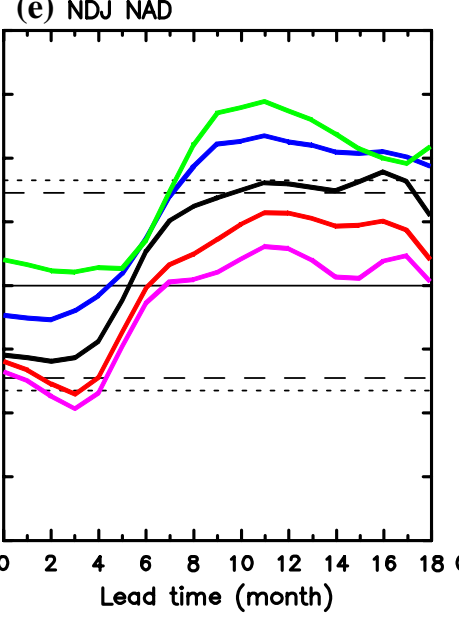

(c) FMA SIOD

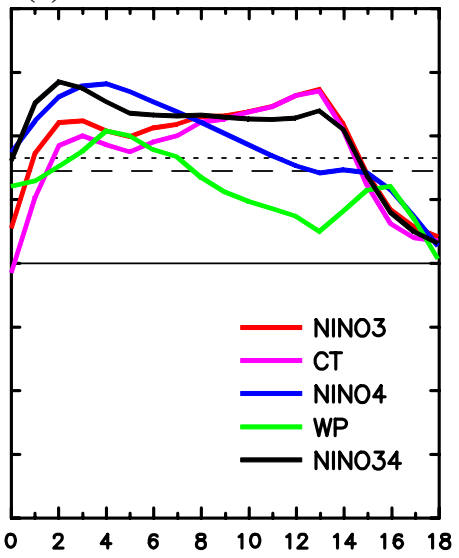

(f) NDJ NPO

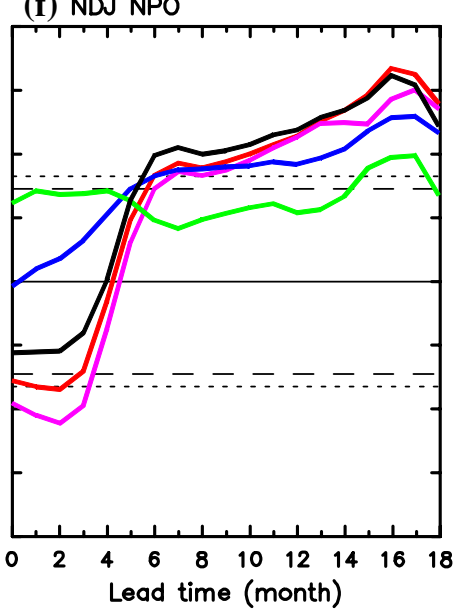

Fig. 7 Lag correlations of the Niño indices with the a IOD in SepOct-Nov (SON), b NTA in Feb-Mar-Apr (FMA), c SIOD in FMA, d SAOD in FMA, e NAD in Nov-Dec-Jan (NDJ), and $\mathbf{f}$ NPO in NDJ after excluding the Niño3.4 SST signal in the previous Dec-Jan-Feb
(DJF) season during the period of 1982-2016. The dotted (dashed) line indicates significance at the $95 \%$ (90\%) confidence level. The lead time indicates that the Niño indices are lagged

and the Niño4 index in the following autumn-early winter seasons, even though a significant improvement is only observed when the NAD leads the WPI by approximately 10 months (Fig. 8w-s). Similarly, the NPO index in NDJ has a significant in-phase relationship with all the Niño indices except WPI for a lead of approximately 6 months or longer (Fig. 7f); however, no significant improvement is obtained in the prediction of any of the Niño indices when adding the NPO precursor to the benchmark model (Fig. 8a-e).

\subsection{Dependence on the equatorial Pacific WWV and ZWS indices}

According to the recharge oscillator mechanism (Jin 1997a, b), the evolutions of the two types of ENSO are intimately related to the equatorial Pacific WWV and ZWS anomalies (Ren and Jin 2013). Even though the physical processes responsible for the linkage of the IOD, NTA SST anomalies, early winter can increase the prediction skills of the WPI 

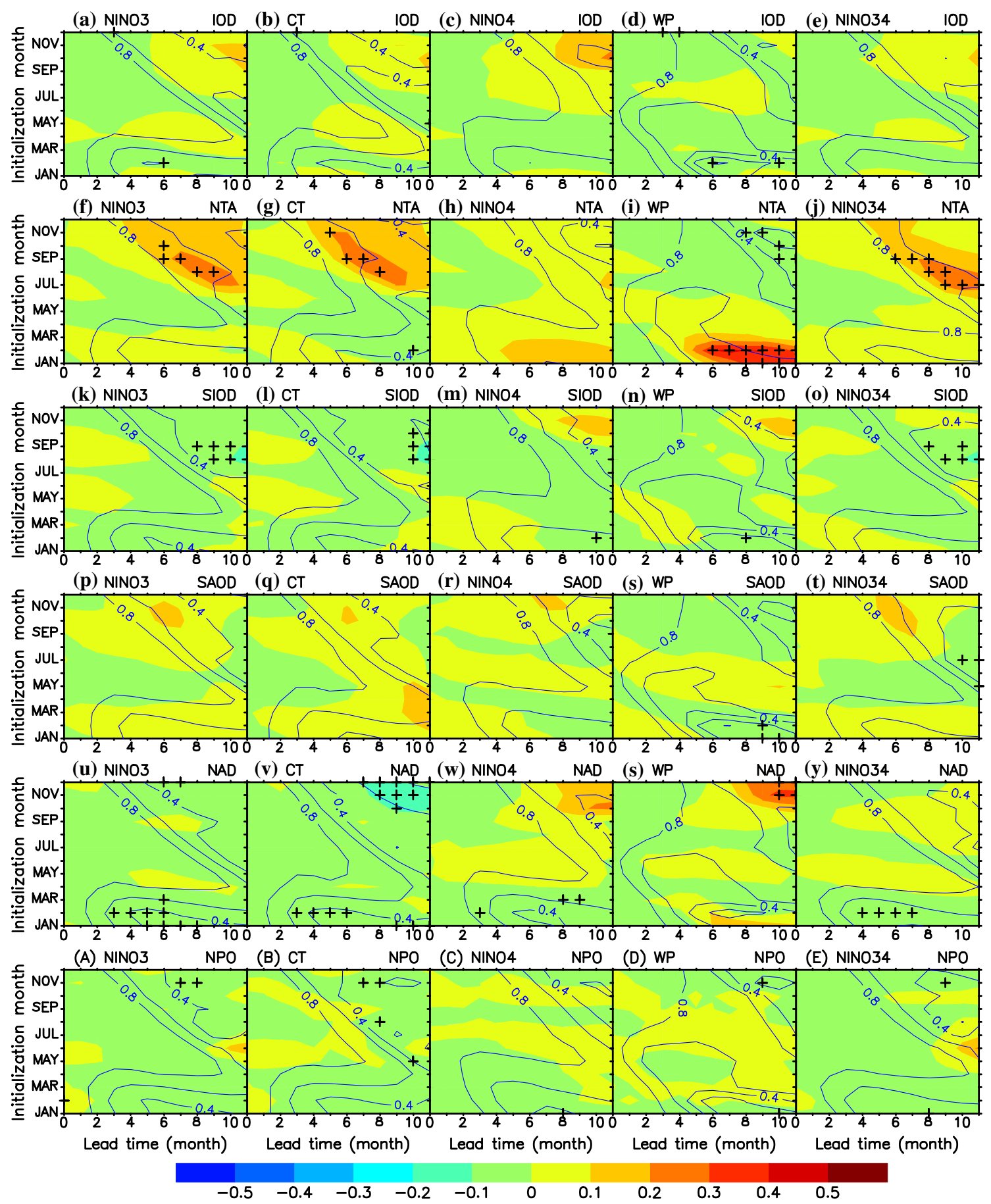

Fig. 8 Cross-validated correlation skill scores (contours) for the a Niño3, b CT, c Niño4, d WP, and e Niño3.4 indices predicted when adding the IOD precursor to the benchmark model and their differences (shading) relative to the benchmark skill scores during the period of 1982-2016. Crosses indicate that the difference is significant at the $95 \%$ confidence level. $\mathbf{f}-\mathbf{y}$ and $\mathbf{a}-\mathbf{e}$ are the same as $\mathbf{a}-\mathbf{f}$ but for the NTA, SIOD, SAOD, NAD, and NPO precursors, respectively

To examine whether the impacts of the aforementioned precursors on the prediction skills of the Niño indices are related to the WWV and/or ZWS anomalies that might be remotely initialized by affecting the equatorial Pacific atmosphere-ocean conditions, we perform two sensitivity 
experiments. That is, we exclude either the ZWS or WWV precursor from the benchmark model and then recalculate the prediction skills of the Niño indices by individually adding other precursors into this new benchmark model. Figures 9 and 10 show the corresponding cross-validated TCC skill scores of the Niño indices and their differences relative to the benchmark skill scores.
A comparison of Fig. 9 with Fig. 8 indicates that the improvement in the prediction skills of the Niño4 index and the WPI caused by the use of the NTA and NAD precursors becomes more obvious when the ZWS precursor is excluded from the benchmark model. In particular, the NTA precursor in January-April can significantly improve the prediction skill of the WPI in the following autumn-winter seasons and
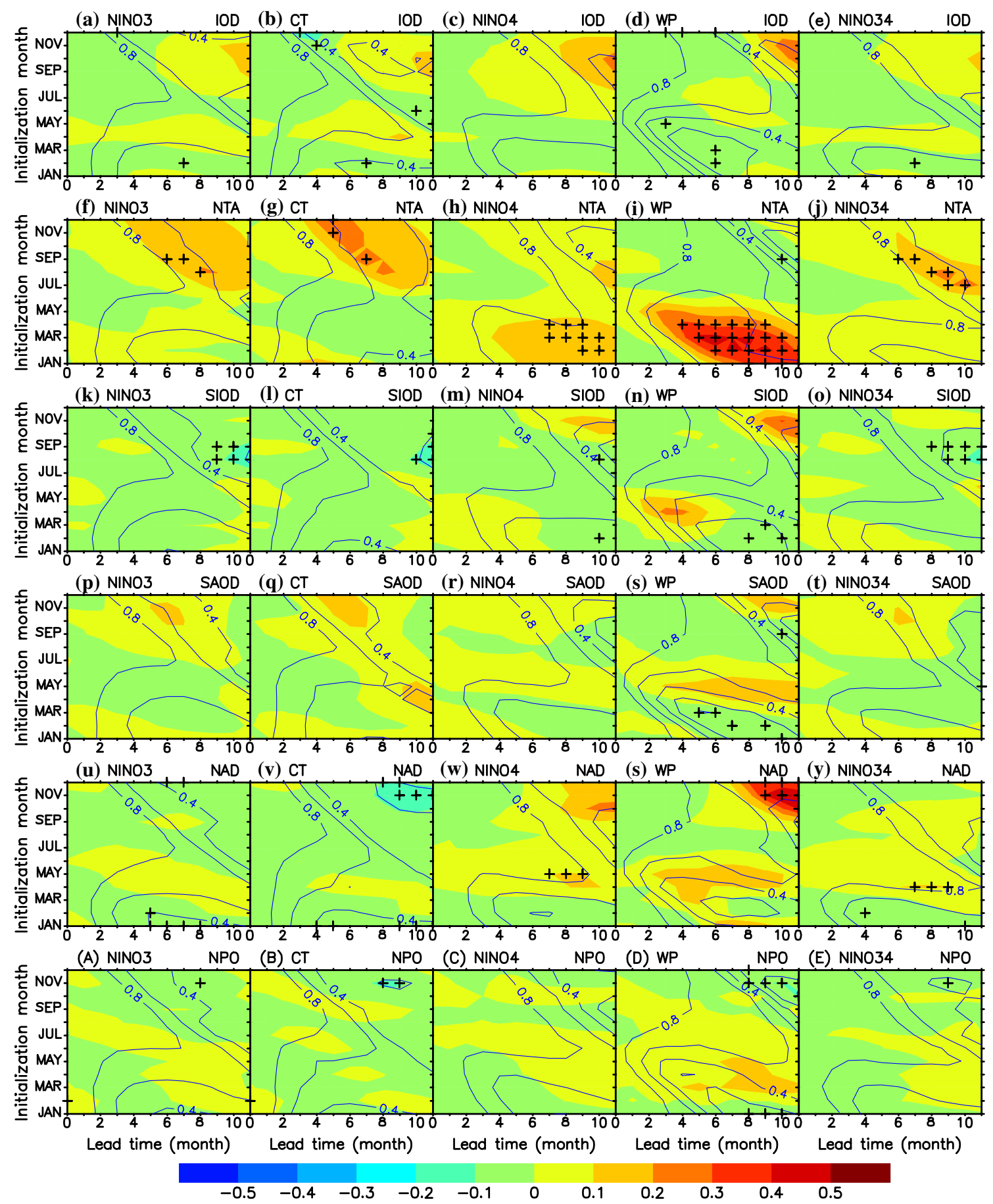

Fig. 9 The same as Fig. 8, but for the skill scores excluding the ZWS precursor from the benchmark model 

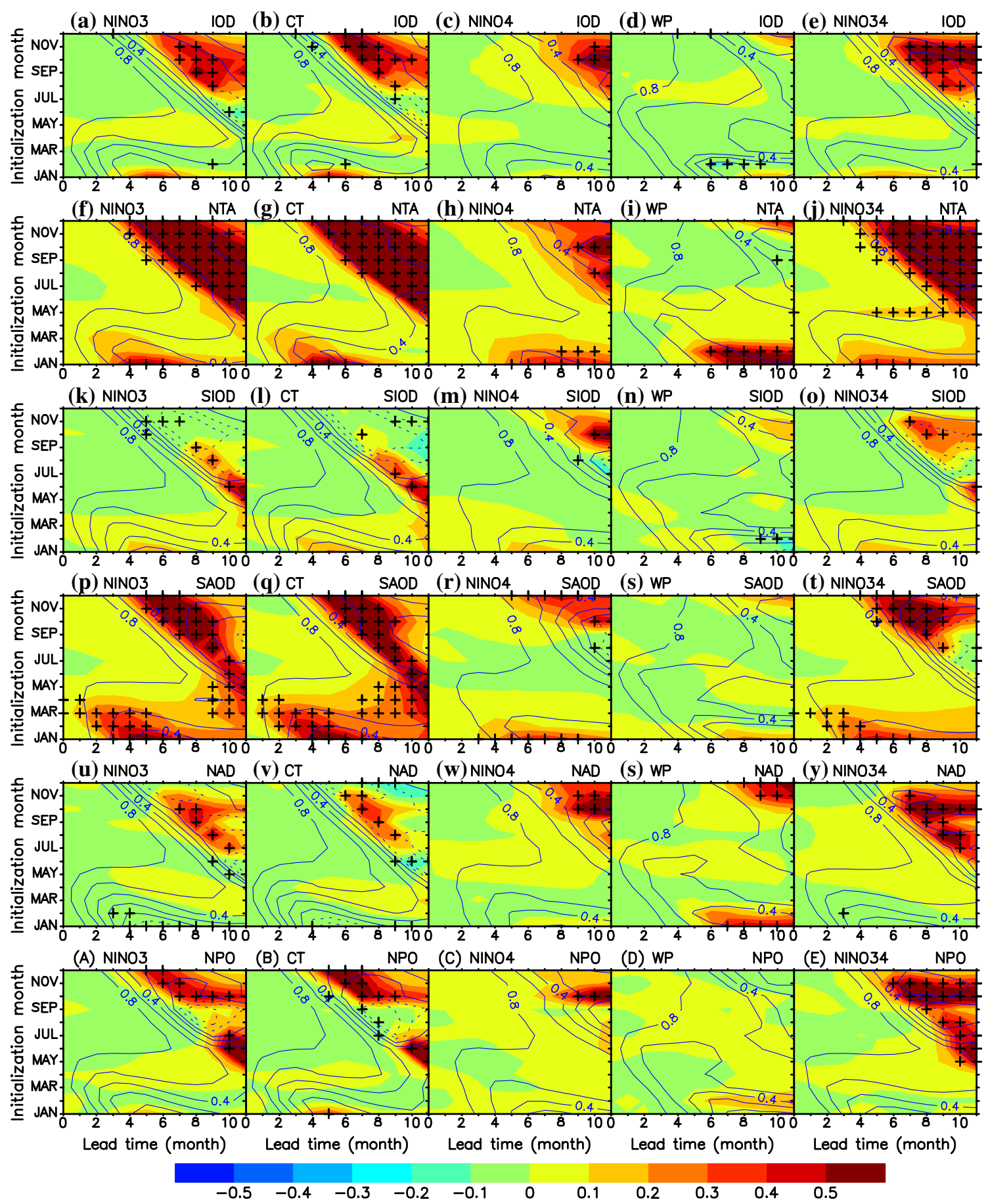

Fig. 10 The same as Fig. 8, but for the skill scores excluding the WWV precursor from the benchmark model

that in late summer-autumn can significantly contribute to improvement of prediction of the two EP ENSO indices during the next spring when excluding the ZWS precursor from the benchmark model (Fig. 9i). However, the improvement in predicting the Niño indices by other precursors based on a benchmark model excluding the ZWS signal is similar to that in the benchmark model including both the WWV and
ZWS signals. This clearly suggests that the NTA SST and NAD act to inject remote signals into the equatorial Pacific ZWS anomalies that tend to initialize the CP ENSO, and the NTA SST also contribute to improving predictions of the EP ENSO in the following spring, whereas the information from other precursors is weakly involved in the ZWS signals. 
Conversely, the comparison of Fig. 10 with Fig. 8 shows a pronounced improvement in the prediction skills of the Niño indices except WPI caused by the use of the IOD, NTA, SAOD, and NPO precursors across the SPB domain when the WWV precursor is excluded from the benchmark model; such an improvement is also seen for the SIOD and NAD precursors but covers much smaller domains. For the WPI, the improvement in the prediction skills in the autumn-winter seasons caused by the use of the NAD precursor in the previous winter becomes significant and more pronounced (Figs. 8s, 10s) and the improvement caused by the use of the NTA precursor in the previous winter becomes slightly higher in this case (Figs. 8h, 10h). These results indicate that the influences of most of the external precursors on ENSO are realized via the initialization of the WWV anomalies for the Niño indices. In other words, external precursors do not increase the ENSO prediction skill unless they introduce extra effective signals into the benchmark model in which both the WWV and ZWS precursors are included.

These results suggest that the ENSO precursors from outside the tropical Pacific that are focused on in this study all have an impact on the prediction skills of the Niño indices. The pronounced impacts of the IOD, SAOD, and NPO anomalies primarily occur across the SPB only when excluding the WWV precursor from the benchmark model. Conversely, the NTA SST and NAD anomalies during the winter-spring seasons have a significant impact on the prediction skills of the Niño4 index and the WPI during the following autumn-winter seasons, which becomes more significant when excluding either the WWV or ZWS precursor from the benchmark model. Note that the NTA SST anomalies also have a pronounced impact on the prediction skills of the CTI and the Niño3 and Niño3.4 indices across the SPB, which can only be detected when excluding the WWV precursor from the benchmark model. Based on Figs. 8, 9 and 10 , it can be inferred that the NTA SST anomalies in the previous winter-spring seasons supply extra signals compared to the WWV and ZWS for the following autumn-winter generation of both types of ENSO.

To support the above conclusions, Fig. 11 further shows the correlations of the SON IOD, NDJ SAOD, FMA NTA, and NDJ NAD indices with the WWV and ZWS indices from which the impacts of Niño3.4 SST signal in the previous DJF season have been linearly removed. These precursors (i.e., IOD, SAOD, NTA, and NAD) at the corresponding specific seasons are chosen according to the results shown in Figs. 8, 9 and 10. That is, the impact of the IOD in SON and SAOD in NDJ on the prediction skills of the Niño3 index and the CTI primarily depends on the equatorial Pacific WWV anomalies, while the impact of the NTA SST in FMA and NAD in NDJ on the prediction skills of the Niño4 index and the WPI is related to both the equatorial Pacific WWV and ZWS anomalies.
As seen in Fig. 11a, b, both the IOD index in SON and the SAOD index in NDJ are highly correlated with the WWV index when the former two lead by approximately 2-3 months or longer; however, their correlations with the ZWS index are relatively weak when they lead by 3-12 months. Conversely, the NTA index in FMA has a significant correlation with the ZWS (WWV) index in the following 0-12 (3-8) months, even though the lag correlations for the WWV index are somewhat weaker than those for the ZWS index over a lag time range of 3-8 months (Fig. 11c). The correlations of the NAD index in NDJ with the WWV index are comparable to those of the ZWS index in the following months and become significant when the former leads the latter two by approximately 6 months or longer (Fig. 11d). These consistent results confirm our conclusions regarding the relationship of the precursors from outside the tropical Pacific with the equatorial Pacific WWV and ZWS anomalies and therefore explain their effects on the prediction skills of the Niño indices.

\section{Establishment and evaluations of models for the two ENSO types}

The analysis has demonstrated that the NTA SST during the middle winter-early spring (late summer-early autumn) can significantly improve the predictions of the WP (EP) ENSO indices in the following months, while the other precursors from outside the tropical Pacific that are focused on in this study have limited contributions to improving the prediction skills of both types of ENSO relative to the benchmark model built with the equatorial Pacific WWV and ZWS precursors. We further attempt to improve the statistical prediction skills of the Niño indices for the two types of ENSO by conditionally introducing the NTA precursor into the benchmark model as follows:

$\operatorname{Niño}(t)=\alpha \operatorname{Niño}(t)+\beta \mathrm{WWV}(t)+\gamma \mathrm{ZWS}(t)+\delta \operatorname{NTA}(t)$.

Here, $\delta$ is a new parameter corresponding to the new term relative to Eq. (1). In the equation, the NTA precursor to be added to the benchmark model depends on the initial calendar months for the EP and CP ENSO indices. For the EP-type (CP-type) indices, including the CTI and Niño3 (WPI and Niño4) indices, the NTA precursor is added to the benchmark model for the initial months from July to December (from January to June), while for the Niño3.4 index the NTA precursor is added for all the initial months.

Figure 12 presents the cross-validated TCC skill scores of the Niño indices predicted when conditionally adding the NTA precursor to the benchmark model and their differences relative to the benchmark skills for all the months combined. The TCC skill scores are higher than 0.6 for 
Fig. 11 Lag correlations of the WWV and ZWS indices with the a SON IOD, b NDJ SAOD, c FMA NTA, and d NDJ NAD indices after excluding the Niño3.4 SST signal in the previous DJF season during the period of 1982-2016. The dotted (dashed) line indicates significance at the $95 \%$ (90\%) confidence level. The lead time indicates that the WWV and ZWS indices are lagged (a) SON IOD

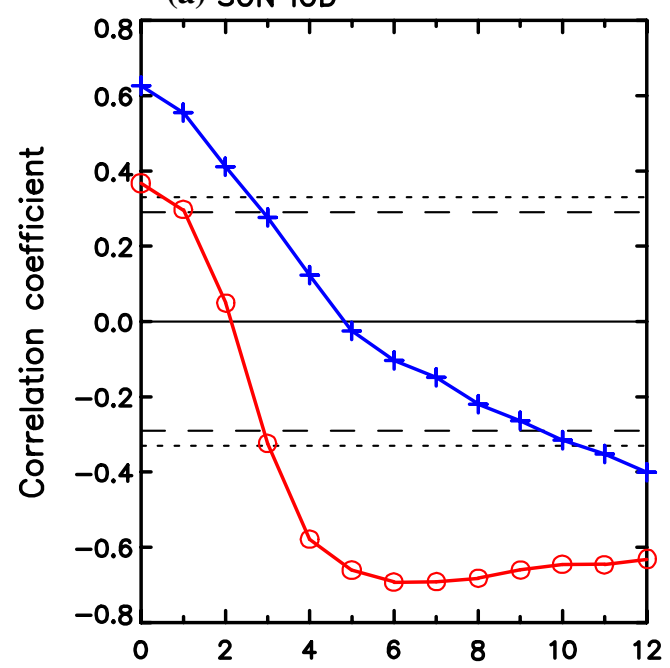

(c) FMA NTA

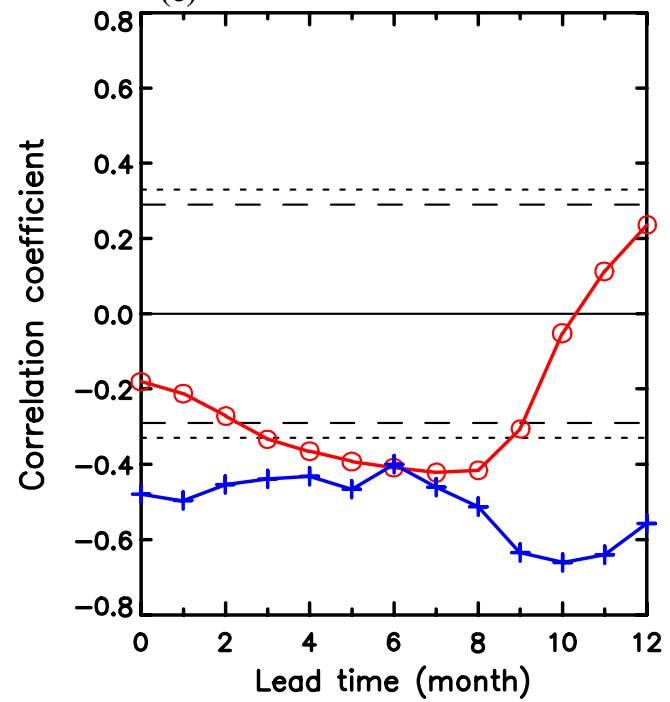

(b) NDJ SAOD

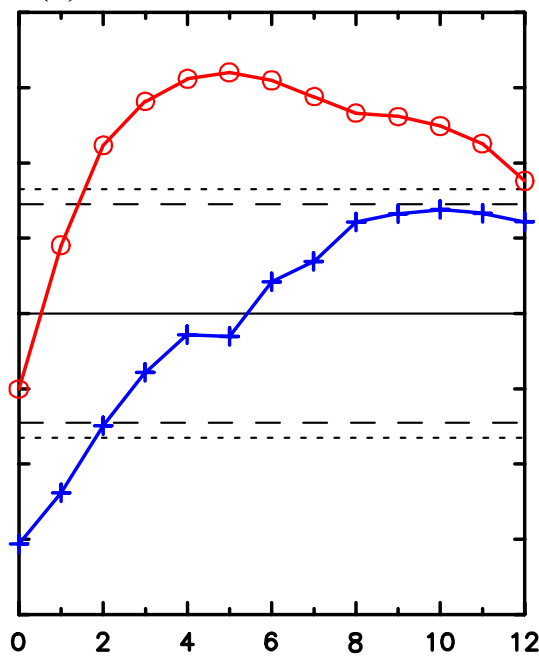

(d) NDJ NAD

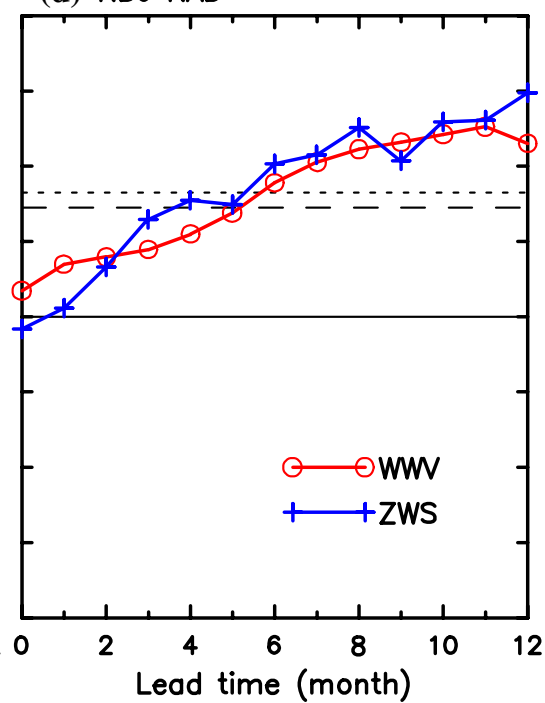

all the Niño indices for a lead of 6 months (Fig. 12a), and significant improvements are observed for most leads in the range of 3-11 months when conditionally adding the NTA precursor to the benchmark model (Fig. 12b). The Niño3.4 and Niño4 indices have the highest TCC skill scores compared to the other Niño indices for leads in the range of $0-11$ months, with values of 0.79 and 0.77 for a lead of 6 months, respectively. Conversely, the WPI and EMI have the lowest skill scores for leads shorter than 7 months, with values of 0.63 and 0.61 for a lead of 6 months, respectively. For the Niño3 index and the WPI (CTI), the TCC skill score is still higher than 0.6 for a lead of 8 (7) months. In short, these results suggest that the prediction skills of both the EP-type and CP-type indices of ENSO can be further improved by conditionally considering the NTA SST signal in a statistical model that includes the equatorial Pacific WWV and ZWS precursors.
We further demonstrate that the improvement in the prediction skills depends on the initial/target months, as shown in Fig. 13. It is clear that the skill scores at nearly all the target and lead months increased after conditionally introducing the NTA precursor to the benchmark model and that all the apparent skill score increases appear over the domains where the benchmark skill scores are relatively low. The patterns of the skill increments are different for the EP and CP ENSO types due to the conditionally involved NTA SST precursors. Further, it is found that introducing the NTA precursor to the benchmark model weakened the intensity of the predictability barriers of the Niño indices for either type of ENSO compared to the benchmark model, as seen by comparing Fig. 14 with Fig. 6, where the maxima of the decline rate of the skill scores is weakened along the barriers of the predictability. 
(a) TCC skills

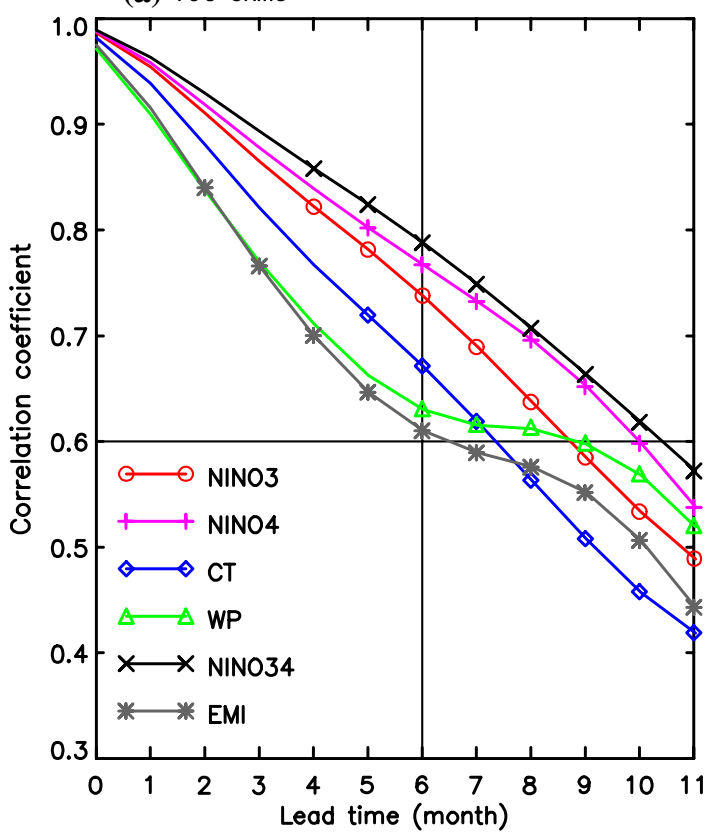

(b) Difference of skills

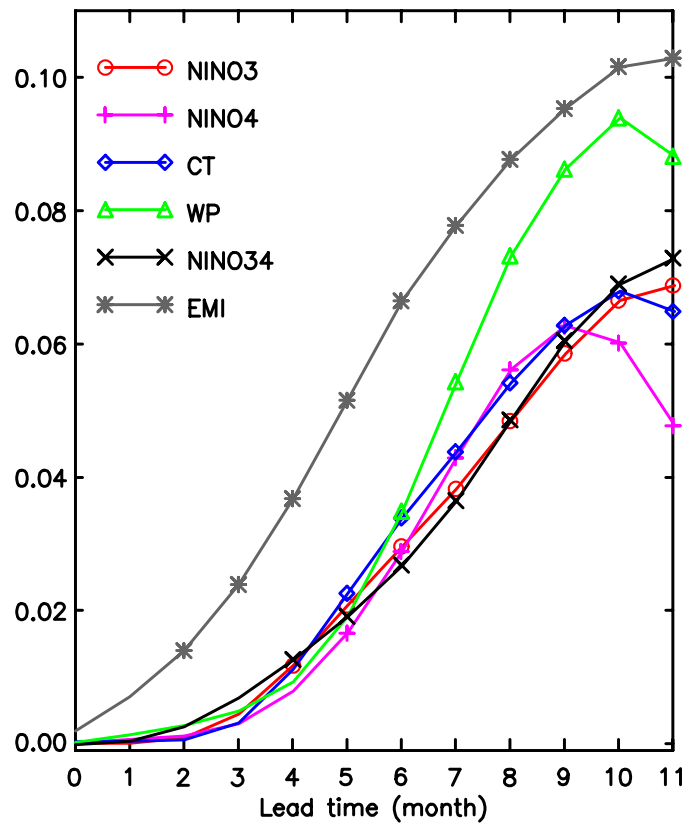

Fig. 12 The same as Fig. 3, but for a the skill scores when conditionally adding the NTA precursor to the benchmark model and $\mathbf{b}$ their improvements relative to the benchmark skills

\section{Summary and discussions}

The two observed types of ENSO, as a manifestation of the diversity of ENSO, have drawn much attention in recent decades. Due to their distinct impacts on global climate, research concerning the prediction and predictability of the two ENSO types has become increasingly important. Realtime operational prediction of the two types of ENSO has been routinely performed since the 2014-2016 El Niño event (Ren et al. 2016b). However, as mentioned in the introduction, the current generation of climate models has a limited ability to reproduce the typical observed features of the two ENSO types; therefore, it is difficult to distinguish between them in most operational dynamical forecasting systems. In this study, we examined the predictability of the two types of ENSO by building up statistical models that include both the equatorial Pacific WWV and ZWS precursors as a benchmark version and attempted to involve several external precursors from outside the tropical Pacific to further improve the statistical models.

Our results show that the preceding variations of the equatorial Pacific WWV and ZWS, which represent the ENSO-related zonally uniform and contrasted thermocline variability patterns, respectively, contribute to the main statistical predictability of the Niño indices that are used to represent ENSO in terms of the two types. Note that the ZWS precursor has been distinctly defined in the models for the EP and CP ENSO indices. The benchmark statistical model has a higher skill score for both the EP and CP ENSO indices than the persistence forecast, and the improvement in skill score is more pronounced for the EP type than that for the CP type. As a comparison, both the traditional Niño3 and Niño4 indices, which combine signals from both types, are relatively more statistically predictable than the Niño indices that individually represent the two ENSO types. Moreover, the prediction skill scores of the EP ENSO indices in the benchmark model are higher during boreal autumn and winter but much lower during spring and summer, whereas those of the CP ENSO indices appear to be higher during winter and spring but lower during late summer and autumn. The evident skill superiority provided by the WWV and ZWS precursors, compared to the persistence forecast, primarily occurs during the predictability barrier and afterwards.

We further examined the impacts of the precursors from the tropical Indian and Atlantic oceans, as well as the extratropics, including the IOD, NTA SST, SIOD, SAOD, NAD, and NPO, which could be considered to be ENSO predictor candidates as revealed in previous studies (e.g., Izumo et al. 2010; Boschat et al. 2013; Ham et al. 2013a; Ding et al. 2017), on the prediction skills of the Niño indices. The results show that all the external precursors that are focused on in this study, except the NTA SST, only make limited contributions to improving the prediction skills of the two ENSO types at specific initial months and leads, compared to a benchmark model built using both the WWV and ZWS precursors. It is found that the NTA SST anomalies can 
(a) NINO3

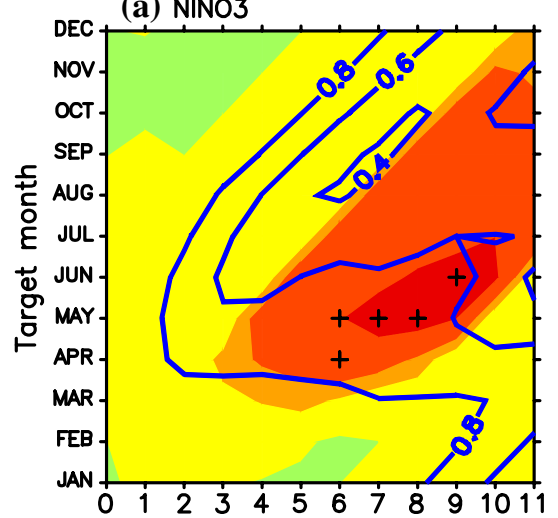

(d) $\mathrm{NINO} 4$

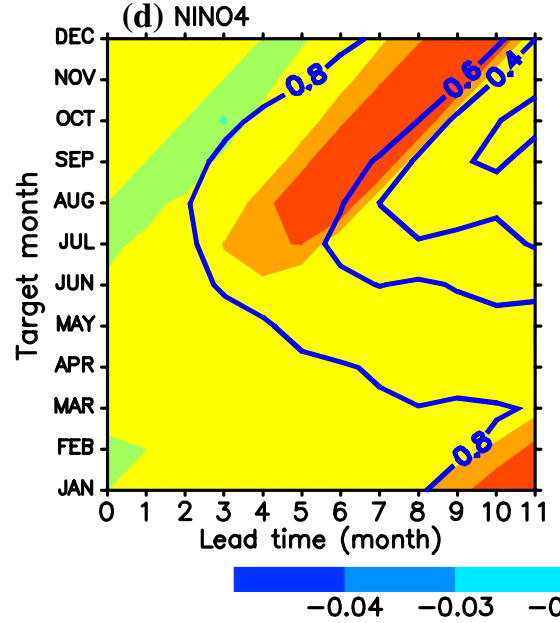

(b) CT

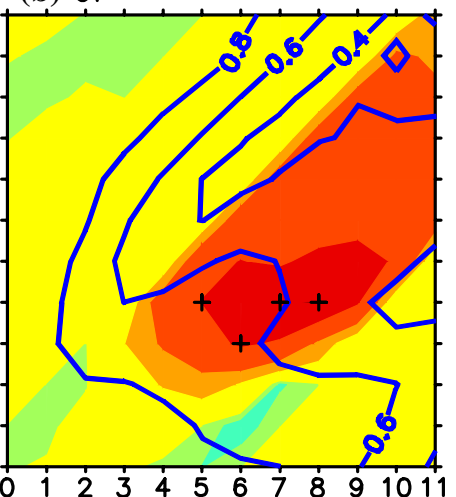

(e) WP

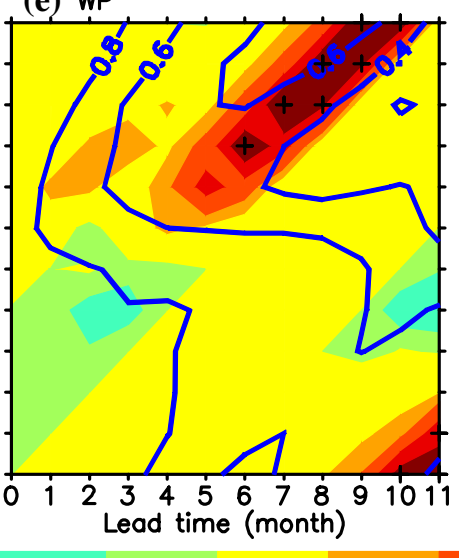

(c) NINO34

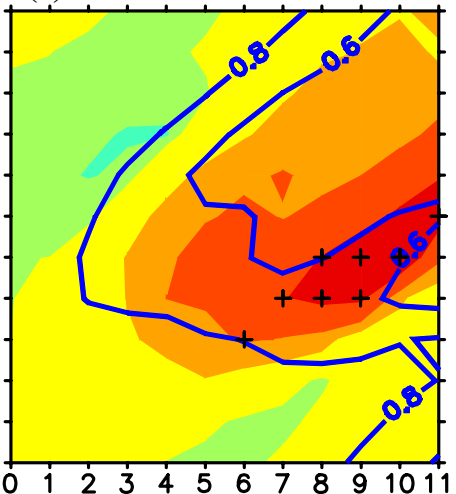

(f) $\mathrm{EMI}$

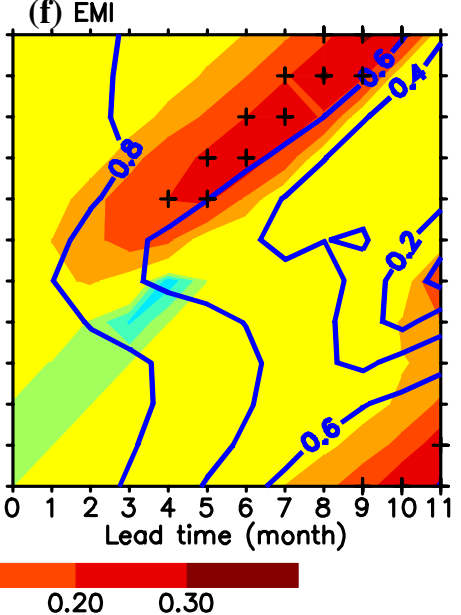

Fig. 13 The same as Fig. 4, but for the skill scores when conditionally adding the NTA precursor to the benchmark model (contours) and their differences relative to the benchmark skills (shading)

reliably provide significant increases in the prediction skill scores for the different types of Niño indices relative to the benchmark skill score. We further demonstrate that the signals of some ENSO precursors, such as the IOD, SIOD, SAOD, NAD, and NPO, which are known to predict ENSO at specific initial or target months, have been already transferred most of their signals into variations in the equatorial Pacific WWV and ZWS anomalies. Note that these external precursors are used at all initial/target months as predictors in the statistical models in this study, as opposed to being locked to certain seasons as mentioned in previous studies. If focusing on the ENSO prediction at some specific initial/ target month, it is possible to use these particular external precursors to set up the statistical models. Indeed, for operational use, relatively general statistical models that involve stably effective, highly independent, and high-performance precursors are needed.

Finally, we configured a new statistical model for the Niño indices of the two ENSO types by conditionally adding the NTA precursor to the benchmark model. It is demonstrated that the Niño3.4 index has the highest prediction skill, compared to the other Niño indices. The statistical predictabilities of the Niño indices representing the two types of ENSO are very different; this is the Niño indices of EP ENSO (i.e., the Niño3 index and CTI) have an overall higher prediction skill than those of CP ENSO (i.e., WPI and EMI). However, such skills usually differ between different initial months and are subject to different predictability barrier properties, such as timing and intensity. The different Niño indices tend to have similar predictability barriers, and the EP ENSO indices show a stronger barrier than the CP ENSO indices but with similar timing. Introducing the NTA precursor tends to weaken the intensity of the barriers for both ENSO types, compared to that of the benchmark model.

Moreover, our results also showed that features in the statistical predictability and prediction skill of the Niño3.4 index are more similar with those of the Niño3 index and CTI, compared to the Niño4 index and WPI, indicating that the Niño3.4 index more reflects the variation in the EP ENSO type than the CP type. To further apply our results to real forecast, we suggest that the Niño3 index can be preferentially used for EP ENSO predictions and that WPI is still preferential for CP ENSO predictions because the 


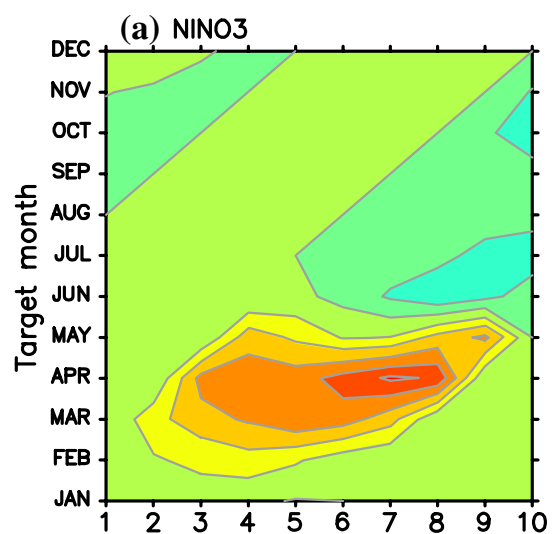

(d) NINO4

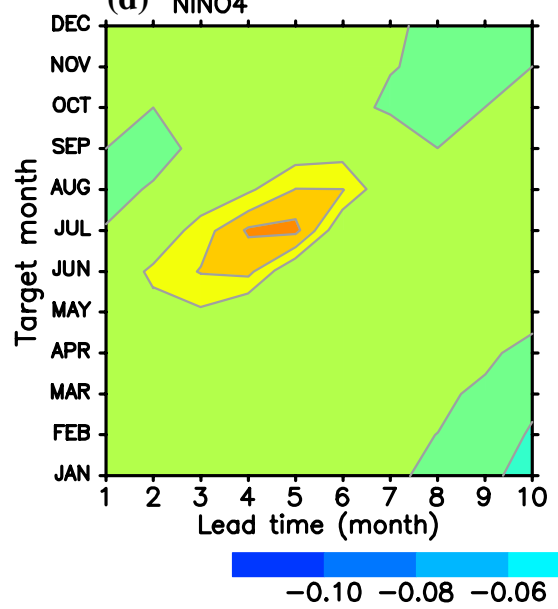

$-0.10-0.08-0.06-0.04-0.02$ (b) $\mathrm{CT}$

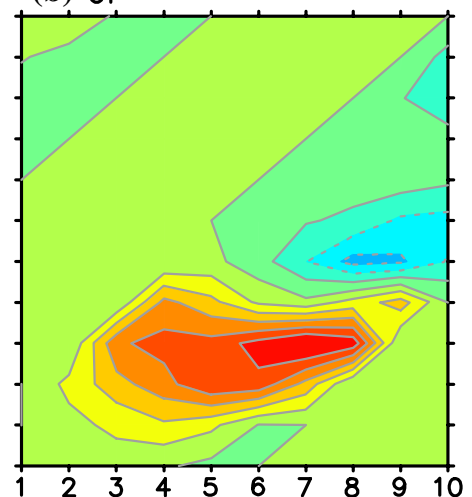

(e) WP

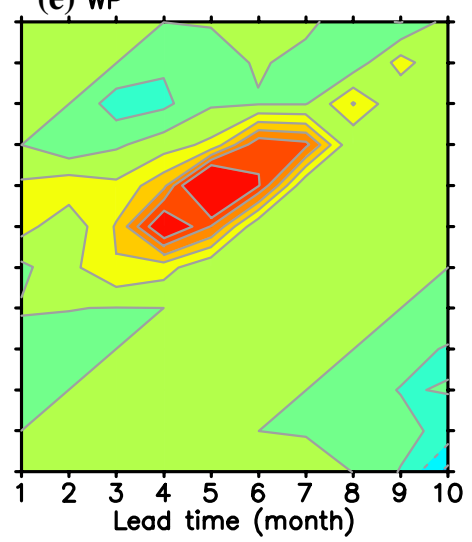

(c) NINO34

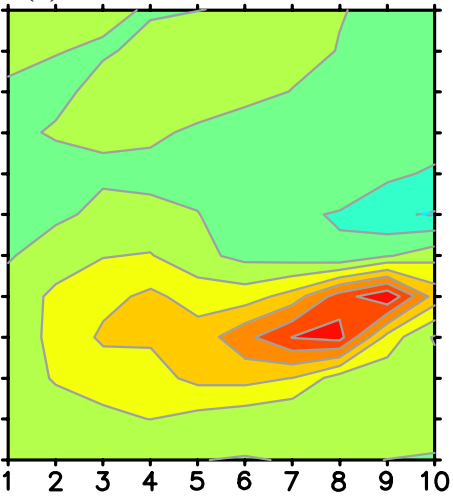

(f) $\mathrm{EMI}$

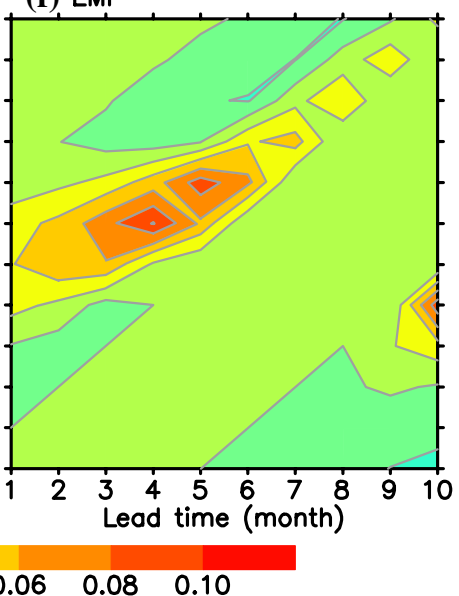

Fig. 14 Difference in the decline rate of the cross-validated correlation skill scores between the scheme conditionally adding the NTA precursor and the benchmark model (former minus latter) for the a
Niño3, b CT, c Niño3.4, d Niño4, e WP, and f EMI indices during the period of 1982-2016
Niño3 index is highly correlated with CTI and has a higher prediction skill.

A statistical model is still a good method to predict the two ENSO types by simply inputting a few easily calculated indices that are available in real time. This is an advantage of statistical model compared to climate models whose prediction performance usually degrades as they are operated in real time. In future, more studies need to be conducted to better predict the two types of ENSO and studies concerning their predictability and prediction methodology also need to be developed.

Acknowledgements This work is jointly supported by National Key Research and Development Program of China (2017YFC1502302), China Meteorological Special Project (GYHY201506013), and the 973 Program of China (2013CB430203). Yi Deng is supported by the National Science Foundation Climate and Large-Scale Dynamics (CLD) program through Grants AGS-1354402 and AGS-1445956.
Open Access This article is distributed under the terms of the Creative Commons Attribution 4.0 International License (http://creativeco mmons.org/licenses/by/4.0/), which permits unrestricted use, distribution, and reproduction in any medium, provided you give appropriate credit to the original author(s) and the source, provide a link to the Creative Commons license, and indicate if changes were made.

\section{References}

Ashok K, Behera SK, Rao SA, Weng H, Yamagata T (2007) El Niño Modoki and its possible teleconnection. J Geophys Res 112:C11007. https://doi.org/10.1029/2006JC003798

Barnston AG, Glantz M, He Y (1999) Predictive skill of statistical and dynamical climate models in SST forecasts during the 1997-98 El Niño and the 1998 La Niña onset. Bull Am Meteor Soc 80:217243. https://doi.org/10.1175/1520-0477(1999)080\%3C021 7:PSOSAD\%3E2.0.CO;2 
Barnston AG, Tippett MK, L'Heureux ML, Li S, Dewitt DG (2012) Skill of real-time seasonal ENSO model predictions during 2002 11: Is our capability increasing? Bull Am Meteor Soc 93:631-651. https://doi.org/10.1175/BAMS-D-11-00111.1

Behringer DW, Xue Y (2004) Evaluation of the global ocean data assimilation system at NCEP: The Pacific Ocean. Eighth Symposium on integrated observing and assimilation systems for atmosphere, oceans, and land surface, AMS 84th Annual Meeting. Washington State Convention and Trade Center, Seattle, Washington, pp 11-15

Bejarano L, Jin F-F (2008) Coexistence of equatorial coupled modes of ENSO. J Clim 21:3051-3067. https://doi.org/10.1175/2007J CLI1679.1

Boschat G, Terray P, Masson S (2013) Extratropical forcing of ENSO. Geophys Res Lett 40:1605-1611. https://doi.org/10.1002/ grl.50229

Brönnimann S (2007) The impact of El Niño-southern oscillation on European climate. Rev Geophys 45:RG3003. https://doi. org/10.1029/2006RG000199

Cane MA, Zebiak SE, Dolan SC (1986) Experimental forecasts of El Niño. Nature 321:827-832

Chang P, Zhang L, Saravanan R, Vimont DJ, Chiang JCH, Ji L, Seidel H, Tippett MK (2007) Pacific meridional mode and El Niñosouthern oscillation. Geophys Res Lett 34:L16608. https://doi. org/10.1029/2007GL030302

Chen D, Zebiak SE, Busalacchi AJ, Cane MA (1995) An improved procedure for El Niño forecasting: implications for predictability. Science 269:1699-1702. https://doi.org/10.1126/scien ce.269.5231.1699

Clarke AJ (2014) El Niño physics and El Niño predictability. Ann Rev Mar Sci 6:79-99. https://doi.org/10.1146/annurev-marine-01021 3-135026

Clarke AJ, Van Gorder S (2001) ENSO prediction using an ENSO trigger and a proxy for western equatorial Pacific warm pool movement. Geophys Res Lett 28:579-582. https://doi. org/10.1029/2000GL012201

Clarke AJ, Van Gorder S (2003) Improving El Niño prediction using a space-time integration of Indo-Pacific winds and equatorial Pacific upper ocean heat content. Geophys Res Lett 30:1399. https ://doi.org/10.1029/2002GL016673

Clarke AJ, Van Gorder S, Colantuono G (2007) Wind stress curl and ENSO discharge/recharge in the equatorial Pacific. J Phys Oceanogr 37:1077-1091. https://doi.org/10.1175/JPO3035.1

Deng Y, Park T, Cai M (2012) Process-based decomposition of the global surface temperature response to El Niño in boreal winter. J Atmos Sci 69:1706-1712. https://doi.org/10.1175/ JAS-D-12-023.1

Ding R, Li J, Tseng Y, Sun C, Zheng F (2017) Linking a sea level pressure anomaly dipole over North America to the central Pacific El Niño. Clim Dyn 49:1321-1339. https://doi.org/10.1007/s0038 2-016-3389-8

Drosdowsky W (2006) Statistical prediction of ENSO (Niño 3) using sub-surface temperature data. Geophys Res Lett 33:L03710. https ://doi.org/10.1029/2005GL024866

Fu C, Diaz HF, Fletcher JO (1986) Characteristics of the response of sea surface temperature in the central Pacific associated with warm episodes of the southern oscillation. Mon Weather Rev 114:17161739. https://doi.org/10.1175/1520-0493(1986)114\%3C171 6:COTROS\%3E2.0.CO;2

Ham Y-G, Kug J-S (2012) How well do current climate models simulate two types of El Niño? Clim Dyn 39:383-398. https://doi. org/10.1007/s00382-011-1157-3

Ham Y-G, Kug J-S, Park J-Y, Jin F-F (2013a) Sea surface temperature in the north tropical Atlantic as a trigger for El Niño/Southern Oscillation events. Nat Geosci 6:112-116. https://doi.org/10.1038/ ngeo1686
Ham Y-G, Kug J-S, Park J-Y (2013b) Two distinct roles of Atlantic SSTs in ENSO variability: north tropical Atlantic SST and Atlantic Niño. Geophys Res Lett 40:1-6. https://doi.org/10.1002/ grl.50729

Hegyi B, Deng Y (2012) A dynamical fingerprint of tropical Pacific sea surface temperatures in the decadal-scale variability of the coolseason Arctic precipitation. J Geophys Res 116:D20121. https:// doi.org/10.1029/2011JD016001

Hegyi B, Deng Y, Black RX, Zhou R (2014) Initial transient response of the winter polar stratospheric vortex to idealized equatorial pacific sea surface temperature anomalies in the NCAR WACCM. J Clim 27:2699-2713. https://doi.org/10.1175/JCLID-13-00289.1

Hendon HH, Lim E, Wang G, Alves O, Hudson D (2009) Prospects for predicting two flavors of El Niño. Geophys Res Lett 36:L19713. https://doi.org/10.1029/2009GL040100

Huang B, Xue Y, Behringer DW (2008) Impacts of Argo salinity in NCEP global ocean data assimilation system: the tropical Indian ocean. J Geophys Res 113:C08002. https://doi. org/10.1029/2007JC004388

Imada Y, Tatabe H, Ishii M, Chikamoto Y, Mori M, Arai M, Watanabe M, Kimoto M (2015) Predictability of two types of El Niño assessed using an extended seasonal prediction system by MIROC. Mon Weather Rev 143:4597-4617. https://doi. org/10.1175/MWR-D-15-0007.1

Izumo T, Vialard J, Lengaigne $M$ et al (2010) Influence of the state of the Indian Ocean dipole on the following year's El Niño. Nat Geosci 3:168-172. https://doi.org/10.1038/ngeo760

Jeong H-I et al (2012) Assessment of the APCC couple MME suite in predicting the distinctive climate impacts of two flavors of ENSO during boreal winter. Clim Dyn 39:475-493. https://doi. org/10.1007/s00382-012-1359-3

Jeong H-I, Ahn J-B, Lee J-Y, Alessandri A, Hendon HH (2015) Interdecadal change of interannual variability and predictability of two types of ENSO. Clim Dyn 44:1073-1091. https://doi. org/10.1007/s00382-014-2127-3

Jin F-F (1997a) An equatorial ocean recharge paradigm for ENSO. Part I: conceptual model. J Atmos Sci 54:811-829. https ://doi.org/10.1175/1520-0469(1997)054\%3C0811:AEORP F\%3E2.0.CO;2

Jin F-F (1997b) An equatorial ocean recharge paradigm for ENSO. Part II: a stripped-down coupled model. J Atmos Sci 54:830 847. https://doi.org/10.1175/1520-0469(1997)054\%3C083 0:AEORPF\%3E2.0.CO;2

Jin EK et al (2008) Current status of ENSO prediction skill in coupled ocean-atmosphere models. Clim Dyn 31:647-664. https:// doi.org/10.1007/s00382-008-0397-3

Kalnay E et al (1996) The NCEP/NCAR 40-year reanalysis project. Bull Am Meteor Soc 77:437-472. https://doi. org/10.1175/1520-0477(1996)077,0437:TNYRP.2.0.CO;2

Kang I-S, Kug J-S (2000) An El-Niño prediction system using an intermediate ocean and a statistical atmosphere. Geophys Res Lett 15:1167-1170

Kao H-Y Yu J-Y (2009) Contrasting eastern-Pacific and centralPacific types of El Niño. J Clim 22:615-632. https://doi. org/10.1175/2008JCLI2309.1

Keenlyside NS, Ding H, Latif M (2013) Potential of equatorial Atlantic variability to enhance El Niño prediction. Geophys Res Lett 40:2278-2283. https://doi.org/10.1002/grl.50362

Kim H-M, Webster PJ, Curry JA (2009) Impact of shifting patterns of Pacific Ocean warming on north Atlantic tropical cyclones. Science 325:77-80. https://doi.org/10.1126/science.1174062

Kirtman PB (2003) The COLA anomaly coupled model: Ensemble ENSO prediction. Mon Weather Rev 131:2324-2341. https ://doi.org/10.1175/1520-0493(2003)131\%3C2324:TCACM E\%3E2.0.CO;2 
Kirtman PB, Min D (2009) Multimodel ensemble ENSO prediction with CCSM and CFS. Mon Weather Rev 137:2908-2930. https ://doi.org/10.1175/2009MWR2672.1

Kirtman BP et al (2014) The North American MultiModel Ensemble (NMME): Phase-1, seasonal-to-interannual prediction; phase-2, toward developing intraseasonal prediction. Bull Am Meteor Soc 95:585-601. https://doi.org/10.1175/BAMS-D-12-00050.1

Kug J-S, Lee J-Y, Kang I-S (2008) Systematic error correction of dynamical seasonal prediction of sea surface temperature using a stepwise pattern project method. Mon Weather Rev 136:35013512. https://doi.org/10.1175/2008MWR2272.1

Kug J-S, Jin F-F, An S-I (2009) Two types of El Niño events: cold tongue El Niño and warm pool El Niño. J Clim 22:1499-1515. https://doi.org/10.1175/2008JCLI2624.1

Larkin NK, Harrison DE (2005a) On the definition of El Niño and associated seasonal average U.S. weather anomalies. Geophys Res Lett 32:L13705. https://doi.org/10.1029/2005GL022738

Larkin NK, Harrison DE (2005b) Global seasonal temperature and precipitation anomalies during El Niño autumn and winter. Geophys Res Lett 32:L16705. https://doi.org/10.1029/2005GL022860

Latif $M$ et al (1998) A review of the predictability and prediction of ENSO. J Geophys Res 103:14375 - 14393. https://doi. org/10.1029/97JC03413

Lim EP, Hendon HH, Hudson D, Wang G, Alves O (2009) Dynamical forecast of inter-El Niño variations of tropical SST and Australian spring rainfall. Mon Weather Rev 137:3796-3810. https://doi. org/10.1175/2009MWR2904.1

Lima CHR, Lall U, Jebara T, Barnston AG (2009) Statistical prediction of ENSO from subsurface sea temperature using a nonlinear dimensionality reduction. J Clim 22:4501-4519. https://doi. org/10.1175/2009JCLI2524.1

Liu Y, Ren H-L (2017) Improving ENSO prediction in CFSv2 with an analogue-based correction method. Int J Clim 37:5035-5046. https://doi.org/10.1002/joc.5142

Luo J-J, Masson S, Behera S, Shingu S, Yamagata T (2005) Seasonal climate predictability in a coupled OAGCM using a different approach for ensemble forecasts. J Clim 18:4474-4497. https:// doi.org/10.1175/JCLI3526.1

Luo J-J, Masson S, Behera S, Yamagata T (2008) Extended ENSO predictions using a fully coupled ocean-atmosphere model. J Clim 21:84-93. https://doi.org/10.1175/2007JCLI1412.1

Meng X-L, Rosenthal R, Rubin DB (1992) Comparing correlated correlation coefficients. Psychol Bull 111:172-175. https://doi. org/10.1037/0033-2909.111.1.172

Mu M, Ren H-L (2017) Enlightenment from researches and predictions of 2014-2016 super El Niño event. Sci China Earth Sci 60:1569-1571. https://doi.org/10.1007/s11430-017-9094-5

Park T, Deng Y, Cai M (2012) Feedback attribution of the El NiñoSouthern oscillation-related atmospheric and surface temperature anomalies. J Geophys Res 117:D23101. https://doi. org/10.1029/2012JD018468

Park J-Y, Yeh S-W, Kug J-S, Yoon J (2013) Favorable connections between seasonal footprinting mechanism and El Niño. Clim Dyn 40:1169-1181. https://doi.org/10.1007/s00382-012-1477-y

Rasmusson EM, Carpenter TH (1982) Variations in tropical sea surface temperature and surface wind fields associated with the southern oscillation/El Niño. Mon Weather Rev 110:354-384. https://doi.org/10.1175/1520-0493(1982)110\%3C0354:VITSS T\%3E2.0.CO;2

Ren H-L, Jin F-F (2011) Niño indices for two types of ENSO. Geophys Res Lett 38:L04704. https://doi.org/10.1029/2010GL046031

Ren H-L, Jin F-F (2013) Recharge oscillator mechanisms in two types of ENSO. J Clim 26:6506-6523. https://doi.org/10.1175/JCLID-12-00601.1
Ren H-L, Jin F-F, Stuecker MF, Xie R (2013) ENSO regime change since the late 1970s as manifested by two types of ENSO. J Meteor Soc Japan 91:835-842

Ren H-L, Liu Y, Jin F-F, Yan Y-P, Liu X-W (2014) Application of the analogue-based correction of errors method in ENSO prediction. Atmos Ocean Sci Lett 7:157-161. https://doi.org/10.3878/j. issn.1674-2834.13.0080

Ren H-L, Jin F-F, Tian B, Scaife AA (2016a) Distinct persistence barriers in two types of ENSO. Geophys Res Lett 43:10973-10979. https://doi.org/10.1002/2016GL071015

Ren H-L, Liu Y, Zuo J, Lu B, Tian B, Jin F-F, Wan J (2016b) The new generation of ENSO prediction system in Beijing Climate Centre and its predictions for the 2014/2016 super El Niño event. Meteorol Mon 42:521-531 (in Chinese)

Ren H-L et al (2017) Prediction of primary climate variability modes in Beijing Climate Center. J Meteor Res 31:204-223. https://doi. org/10.1007/s13351-017-6097-3

Reynolds RW, Rayner NA, Smith TM, Stokes DC, Wang W (2002) An improved in situ and satellite SST analysis for climate. J Clim 15:1609-1625. https://doi.org/10.1175/15200442(2002)015\%3C1609:AIISAS\%3E2.0.CO;2

Rodríguez-Fonseca B, Polo I, García-Serrano J, Losada T, Mohino E, Mechoso CR, Kucharski F (2009) Are Atlantic Niños enhancing Pacific ENSO events in recent decades? Geophys Res Lett 36:L20705. https://doi.org/10.1029/2009GL040048

Ruiz JE, Cordery I, Sharma A (2005) Integrating ocean subsurface temperatures in statistical ENSO forecasts. J Clim 18:3571-3586. https://doi.org/10.1175/JCLI3477.1

Sun C, Li W, Ren H-L, Zhang P, Wang D (2006) A dynamic-analogue error correction model for ENSO prediction and its initial hindcast verification. Chin J Atmos Sci 30:965-976 (in Chinese)

Terray P (2011) Southern hemisphere extra-tropical forcing: a new paradigm for El Niño-southern oscillation. Clim Dyn 36:2171-2199. https://doi.org/10.1007/s00382-010-0825-Z

Tseng Y-H, Hu Z-Z, Ding R, Chen H-C (2017) An ENSO prediction approach based on ocean conditions and ocean-atmosphere coupling. Clim Dyn 48:2025-2044. https://doi.org/10.1007/s0038 2-016-3188-2

Wang R, Ren H-L (2017) The linkage between two ENSO types/modes and the interdecadal changes of ENSO around the year 2000. Atmos Ocean Sci Lett 10:168-174. https://doi.org/10.1080/16742 834.2016 .1258952

Wang X, Wang C (2014) Different impacts of various El Niño events on the Indian Ocean Dipole. Clim Dyn 42:991-1005. https://doi. org/10.1007/s00382-013-1711-2

Wang B et al (2009) Advance and prospectus of seasonal prediction: assessment of the APCC/CliPAS 14-model ensemble retrospective seasonal prediction (1980-2004). Clim Dyn 33:93-117. https:// doi.org/10.1007/s00382-008-0460-0

Wang L, Ren H-L, Chen Q, Tian B, Liu Y (2017) Statistical correction of ENSO prediction in BCC_CSM1.1 m based on a stepwise pattern projection method. Meteorol Mon 43:294-304. (in Chinese)

Weng H, Ashok K, Behera S, Rao AS, Yamagata T (2007) Impacts of recent El Niño Modoki on dry/wet conditions in the Pacific Rim during boreal summer. Clim Dyn 29:113-129. https://doi. org/10.1007/s00382-007-0234-0

Xie R, Jin F-F (2018) Two leading ENSO modes and El Niño types in the Zebiak-Cane model. J Clim 31:1943-1962. https://doi. org/10.1175/JCLI-D-17-0469.1

Xie R, Huang F, Ren H (2013) Subtropical air-sea interaction and the development of central Pacific El Niño. J Ocean Univ China 12:260-271. https://doi.org/10.1007/s11802-013-2143-7

Xue Y, Leetmaa A, Ji M (2000) ENSO prediction with Markov models: the impact of sea level. J Clim 13:849-871. https:// 
doi.org/10.1175/1520-0442(2000)013\%3C0849:EPWMM T\%3E2.0.CO;2

Yang S, Jiang X (2014) Prediction of eastern and central Pacific ENSO events and their impacts on east Asian climate by the NCEP climate forecast system. J Clim 27:4451-4472. https://doi. org/10.1175/JCLI-D-13-00471.1

Yeh S-W, Kug J-S, An S-I (2014) Recent progress on two types of El Niño: observations, dynamics, and future changes. Asia Pac J Atmos Sci 50:69-81. https://doi.org/10.1007/s13143-014-0028-3 2014.

Yeh S-W, Kug JS, Dewitte B, Kwon M-H, Kirtman BP, Jin F-F (2009) El Niño in a changing climate. Nature 461:511-514. https://doi. org/10.1038/nature08316

Yu J-Y, Kim ST (2010) Identification of central-Pacific and easternPacific types of ENSO in CMIP3 models. Geophys Res Lett 37:L15705. https://doi.org/10.1029/2010GL044082

Yu J-Y, Kao H-Y, Lee T (2010) Subtropics-related interannual sea surface temperature variability in the equatorial central Pacific. J Clim 23:2869 - 2884. https://doi.org/10.1175/2010JCLI3171.1

Zebiak SE, Cane MA (1987) A model El Niño-Southern Oscillation. Mon Weather Rev 115:2262-2278

Zhang R-H, Gao C (2016) The IOCAS intermediate coupled model (IOCAS ICM) and its real-time predictions of the 2015-2016 El
Niño event. Sci Bull 61:1061-1070. https://doi.org/10.1007/s1143 4-016-1064-4

Zhang R-H, Zebiak SE, Kleeman R, Keenlyside N (2003) A new intermediate coupled model for El Niño simulation and prediction. Geophys Res Lett 30:2012. https://doi.org/10.1029/2003GL0180 10

Zhang W, Jin F-F, Li J, Ren H-L (2011) Contrasting impacts of twotype El Niño over the western north Pacific during boreal autumn. J Meteor Soc Jpn 89:563-569

Zhang W, Jin F-F, Ren H-L, Li J, Zhao J-X (2012) Differences in teleconnection over the North Pacific and rainfall shift over the USA associated with two types of El Niño during boreal autumn. J Meteor Soc Jpn 90:535-552

Zhang RH, Min Q, Su JZ (2017) Impact of El Niño on atmospheric circulations over east Asia and rainfall in China: role of the anomalous western North Pacific anticyclone. Sci China Earth Sci 60:1124-1132. https://doi.org/10.1007/s11430-016-9026-x

Zhu J et al (2015) ENSO prediction in project minerva: sensitivity to atmospheric horizontal resolution and ensemble size. J Clim 28:2080-2095. https://doi.org/10.1175/JCLI-D-14-00302.1 